\title{
Morphology and Amorphous Structure of Blend Membranes from Cellulose and Casein Recovered from Its Cuprammonium Solution
}

\author{
Guang Yang, ${ }^{*}$ Chihiro Yamane, Toshihiko Matsui, Ikuya Miyamoto, Lina Zhang, ${ }^{*}$ \\ and Kunihiko OкалIma \\ Fundamental Research Laboratory of Natural \& Synthetic Polymers, \\ Asahi Chemical Industry Co., Ltd., \\ 11-7 Hacchownawate, Takatsuki, Osaka 569, Japan \\ * Department of Chemistry, Wuhan University, Wuhan 430072, People's Republic of China
}

(Received August 5, 1996)

\begin{abstract}
Morphology, structure, and some properties of the blend membranes of cellulose/casein prepared from their cuprammonium hydroxide solution by alkali coagulation and subsequent acid neutralization were investigated in connection with the complex forms of cellulose in the mixed solutions and the change in complex forms developed by alkali coagulation. For this purpose, the cast solution was coagulated by either directly immersing the coagulation bath (W series) or after vaporization of ammonia in advance (D series). Circular dichroism (CD) measurements on the mixed solution and gel membranes revealed that the mixed solution with the fraction of casein $f_{\text {cas }} \geqq 0.3$ forms the independent casein/cuprammonium hydroxide complex, hence giving phase-separated state in an optical anisotropic sense, and this upper limit shifts towards lower $f_{\text {cas }}$ $(=0.2)$ during coagulation. Longest wavelength $\lambda$ for the charge transfer excitation of cellulose/cuprammonium complex was seen for the gel membrane with $f_{\text {cas }}=0.1$, where highest tensile strength and crystalline orientation for the membranes are realized. Mechanical relaxation analysis suggests that the amorphous structural formation for $\mathrm{D}$ and $\mathrm{W}$ series membranes are quite different and that for the former is on the whole determined by the existing state of casein and cellulose in the mixed solution not by that in the gel membranes. Except for porosity $\operatorname{Pr}_{\mathrm{a}}$ the swelling anisotropy parameter $L_{\mathrm{t}}$ was not correlated with (110) plane orientation parameter and most amorphous parameters, which control $L_{t}$ of the regenerated cellulose membranes.

KEY WORDS Blend Membrane / Cellulose / Casein / Circular Dichroism Spectra / Mechanical

Relaxation / Tensile Strength / Swelling Anisotropy /
\end{abstract}

Many cellulose blends such as cellulose/polyacrylonitrile, ${ }^{1}$ cellulose/poly (vinyl alcohol) ${ }^{2}$ cellulose/poly( $\varepsilon$ caprolactone), ${ }^{3}$ and cellulose/poly(4-vinylpyridine) ${ }^{4}$ using cellulose solvents recently discovered, such as $N, N$ dimethylacetamide-lithium chloride ${ }^{1-3}$ and dimethyl sulfoxide-paraformaldehyde ${ }^{4}$ have been reported especially discussing "miscibility" of the blends. On the one hand, the cellulose/aqueous (aq) cuprammonium hydroxide solution, discovered by Schweitzer, ${ }^{5}$ still has industrial importance for regenerated cellulose fiber formation in the textile field and the membrane formation in material separation field. Aqueous cuprammonium hydroxide acts some suitable solvent for many kinds of polymers such as polysaccharides, polyglucans, cellulose derivatives, natural proteins (silk fibroin, casein), water soluble synthetic polymers, and so on. This gives a fundamental basis for polymer blends using the cellulose/aq cuprammonium hydroxide system. In fact, we have studied using the above cuprammonium hydroxide solution system the cellulose blend membranes containing casein, ${ }^{6}$ poly(vinyl alcohol) ${ }^{7}$ gelatin, ${ }^{8}$ and polyethylene glycohol ${ }^{8}$ on their mechanical properties, permeability properties, and miscibility using scanning electron microscopy SEM, X-ray diffraction, ${ }^{13} \mathrm{C}$ NMR, and DSC analyses. For the cellulose/casein blend membranes (weight fraction of casein in the membranes $f_{\text {cas }}$ ranging from 0 to 0.33 ) using aq cuprammonium hydroxide solution in general, tensile strength is higher than that of the pure cellulose membrane and a portion of casein is phase-separated at $f_{\text {cas }}=0.33$ but the change in cellulose complex when mixed with casein and the amorphous structures of the blend membranes were not studied in detail.

In another line of studies Okajima and his coworkers have already studied on the dissolved state $\left(\mathrm{C}_{2}, \mathrm{C}_{3}\right.$ coordinate $\delta$ chelate form) of cellulose in cuprammonium hydroxide, ${ }^{9}$ the morphology of the regenerated cellulose membranes recovered from its cuprammonium hydroxide solution in relation to the changes in circular dichroism (CD) spectra of the cellulose solution during its coagulation process, ${ }^{10}$ and the dimensional stability and morphology of the membranes obtained by changing coagulants in view of amorphous parameters. ${ }^{11,12}$ Of the coagulants used, aq sulfuric acid was proved to decompose promptly the original cellulose /cuprammonium hydroxide complex, giving very porous structure, and in contrast, aq sodium hydroxide gives a gel with definite complex form, leading to very dense structure. ${ }^{10}$

Further, we found that morphology and amorphous structure of the regenerated cellulose membranes dramatically changed as functions of both concentration of coagulant and polymer concentration when aq sulfuric acid was used as coagulant. ${ }^{13}$ It is therefore interesting to examine if the above phenomenological observation for the cellulose membranes is also applicable to the cellulose blend membranes.

In this paper, as an extension of the previous study, using a series of cellulose blend membranes containing casein prepared under a coagulation system (1st, aq sodium hydroxide; 2nd, aq sulfuric acid; 3rd, water washing) before or after ammonia evaporation from the cast solution, we attempt to make clear the change in $\mathrm{CD}$ spectra of the mixed solution and the gel films by 1 st coagulant and differentiate the morphologies and struc- 
tures of a series of cellulose blend membranes.

\section{EXPERIMENTAL}

Cellulose Solution, Casein Solution, and Their Mixtures

Cotton linter supplied by Peterdemings Co., Ltd., was dissolved in aq cuprammonium hydroxide solution according to the known procedure ${ }^{9}$ at cellulose concentration of $8 \mathrm{wt} \%$. The molar composition of the solution (cellulose $/ \mathrm{Cu} / \mathrm{NH}_{3}$ ) was adjusted constant as 0.05 / $0.046 / 0.36$. The viscosity-average molecular weight of the cellulose recovered from the above solution by aq sulfuric acid was $1.7 \times 10^{5}$, as estimated by using the equation $[\eta]=3.85 \times 10^{-2} M_{w}{ }^{0.76}$ established for cellulose/cadoxen system. ${ }^{14}$

Casein (number-average molecular weight $M_{n}=1.8 \times$ $10^{4}$ ) was supplied from Katayama Chemical, Japan. It was dissolved in aq $25 \mathrm{wt} \%$ ammonia to the polymer concentration of $20 \mathrm{wt} \%$. These solutions were mixed at room temperature with mechanical stirrer into the blend polymer mixed solution to give desired blend ratios (cellulose/casein $=10 / 0,9 / 1,8 / 2,7 / 3,6 / 4$, and $0 / 10, \mathrm{w} / \mathrm{w}$ ). All the mixed solutions were kept almost transparent. These were subject to the following blend membrane preparation and to circular dichroism (CD) measurements.

\section{Preparation of the Blend Membranes}

The mixed solutions were cast on a glass plate $(20 \times$ $19.4 \mathrm{~cm}$ ) to give thickness of $250 \mu \mathrm{m}$, immediately immersing gently into $500 \mathrm{ml}$ of aq $10 \mathrm{wt} \%$ sodium hydroxide for $1 \mathrm{~min}$, subsequently neutralized by aq sulfuric acid for $1 \mathrm{~min}$, washed by water and acetone to give wet membrane, finally dried in air (W series). In another line of membrane preparation, the cast solution on a glass plate was stood for $40 \mathrm{~min}$ at $30^{\circ} \mathrm{C}$ to evaporate some ammonia, then the same procedure described above was applied for this method (D series). The membranes are coded as $\mathrm{WCe}_{k} \mathrm{Ca}_{n}$ and $\mathrm{DCe}_{k} \mathrm{Ca}_{n}$ (W and D means wet and dry, $k$, cellulose composition in weight basis, $n$, casein composition , $k+n=10$ ). The retention of casein in the blend membranes were examined gravimetrically by referring the total initial charge of polymers with the resultant weight of the dried membranes. In analytical section, however, the initial weight fraction of casein $f_{\text {cas }}$ was used without correction. The casein membrane was also prepared by evaporation of ammonia from casein $/ 25 \mathrm{wt} \%$ aq $\mathrm{NH}_{3}$ solution.

The wet membranes were subjected to scanning electron microscopic (SEM) observation and water permeability UFR measurements, and the dried ones to Xray diffraction and mechanical relaxation measurements as well as mechanical property (tensile strength, tensile elongation) and swelling anisotropy measurements.

\section{Measurement}

CD spectra of the mixed solutions and the gelatinous membranes obtained in the first step of coagulation (aq $\mathrm{NaOH}$ ) described in Table II were recorded on a spectrophotometer (model J-720, JASCO, Japan) at $25^{\circ} \mathrm{C}$ in a quart cell with light pass length of $0.1 \mathrm{~mm}$ under the following operating conditions: Band width, $1.0 \mathrm{~nm}$; sensitivity, $1000 \mathrm{mdeg}$; response, $0.5 \mathrm{~s}$; scanning speed,
$500 \mathrm{~nm} \mathrm{~min}{ }^{-1}$; wave length range, $800-200 \mathrm{~nm}$.

\section{SEM Observation}

The wet membranes were frozen in liquid nitrogen and lyophilized with an apparatus (Type FD-1, Tokyo Rika Machinery Co., Ltd., Japan). The surface (side directly contacted with coagulant) and cracked cross section sputtered with gold were subject to scanning electron microscopic observation at the accelerating voltage of 5 kV (FE-SEM model S-800, Hitachi Co., Ltd., Japan). An apparent porosity $\operatorname{Pr}_{\mathrm{a}}$ can be estimated as $P r_{\mathrm{a}}=100$ $\left(1-\rho_{\mathrm{a}} /\left(\rho_{\text {cell }} f_{\text {cell }}+\rho_{\text {cas }} f_{\text {cas }}\right)\right)$ where $\rho_{\mathrm{a}}, f_{\text {cell }}$ and $f_{\text {cas }}$, and $\rho_{\text {cell }}$ and $\rho_{\text {cas }}$ are apparent density of membrane, the weight fractions of cellulose and casein and their densities, respectively) and $\rho_{\text {cell }}=1.52\left(\mathrm{~g} \mathrm{~cm}^{-3}\right)$ and $\rho_{\text {cas }}=1.30$ $\left(\mathrm{g} \mathrm{cm}^{-3}\right)$ were used.

\section{Swelling Anisotropy Parameter and UFR}

Swelling anisotropy parameters $L_{\mathrm{t}}\left(=d_{\mathrm{w}} / d_{\mathrm{d}} ; d_{\mathrm{d}}\right.$ is thickness in dried state), $L_{1}\left(=l_{\mathrm{w}} / l_{\mathrm{d}} ; l_{\mathrm{w}}\right.$ and $l_{\mathrm{d}}$ are lengths of surface in wet and dried states) and $V_{\mathrm{s}}$ (volumetric swelling degree) were measured according to the previous method. ${ }^{11}$ Water permeability UFR of the wet membranes with area of $2.4 \mathrm{~cm}^{2}$ was estimated from water flux under the pressure difference of $400 \mathrm{mmHg}$ at $25^{\circ} \mathrm{C}$, and expressed as $\mathrm{ml} \mathrm{h}^{-1} \mathrm{~m}^{-2} \mathrm{mmHg}^{-1}$.

\section{X-Ray Diffraction Analysis}

Orientation of crystal planes ((11) 0$)$ and (200)) of the dried membranes was analyzed by irradiating either perpendicular to the cross section (that is, parallel to surface) or to the surface of the membranes by using a X-ray diffractometer (DH0002AM3X, Rigaku Denki Co., Japan). Diffraction intensities $\left(I_{\|(1 \bar{T} 0)}, I_{\perp(1 \bar{I} 0)}\right)$ at $2 \theta=12^{\circ}$ and those $\left(I_{\|(200)}, I_{\perp(200)}\right)$ at $2 \theta=21^{\circ}$ were measured. Orientation factor $f_{\|(1 \overline{1} 0)}$ for $(1 \overline{1} 0)$ plane to the parallel direction to the membrane surface was evaluated according to Takahashi. ${ }^{15}$ Crystallinity $\chi_{\mathrm{c}}$ and apparent crystalline size ACS corresponding to crystalline planes were also estimated by conventional method. ${ }^{16}$

\section{Mechanical Relaxation Measurement}

The visco-elastic properties $\left(\tan \delta-T, E^{\prime}-T\right.$ curves) for the membranes with size of $3 \times 40 \times 0.08 \mathrm{~mm}$ were recorded on a visco-elastic spectrometer (Model SDM5000, Seiko Densi Co., Ltd., Japan) under the following conditions: Frequency, $10 \mathrm{~Hz}$; heating rate, $10^{\circ} \mathrm{C}$ $\min ^{-1}$; measuring interval, $1{ }^{\circ} \mathrm{Cmin}^{-1}$; sample length, $20 \mathrm{~mm}$; adding amplitude, $16 \mu \mathrm{m}$; initial charge to film, $115 \mathrm{~g} \mathrm{~mm}^{-2}$; scanning of temperature range, -150 $350^{\circ} \mathrm{C}$, if not specially indicated.

\section{Mechanical Properties}

Tensile strength $\sigma_{\mathrm{b}}$ and tensile elongation $\varepsilon_{\mathrm{b}}$ of the dry membrane were measured by tensile machine (TENSILE/UTM-III-100, Toyo Baldwin Co., Ltd.) under the following condition: Sample width, $5 \mathrm{~mm}$; sample length, $50 \mathrm{~mm}$ ( $30 \mathrm{~mm}$ between the grips); stretch rate, 30 $\mathrm{mm} \mathrm{min}^{-1}$; humidity, $65 \%$; temperature, $20^{\circ} \mathrm{C}$. 


\section{RESULTS AND DISCUSSION}

Table I collects the retention of casein in the resultant membranes $R e_{\text {cas }}$, the porosity $P r_{\mathrm{a}}$, water permeability UFR, tensile strength $\sigma_{\mathrm{b}}$, tensile elongation $\varepsilon_{\mathrm{b}}$, and swelling anisotropy parameters $\left(L_{\mathrm{t}}, L_{\mathrm{l}}, V_{\mathrm{s}}\right) \cdot R e_{\text {cas }}$ for D series is slightly larger that for $\mathrm{W}$ series and lower with an increase in casein fraction $f_{\text {cas }} . P r_{\mathrm{a}}$ is larger for $\mathrm{D}$ series membranes than those for $\mathrm{W}$ series membranes, probably due to some structural fixation accompanied by evaporation of ammonia in advance for $\mathrm{D}$ series before structural formation during regeneration process. For both series $P r_{\mathrm{a}}$ abruptly increases when weight fraction of casein $f_{\text {cas }}$ reaches 0.4 (in reality 0.37 for $\mathrm{D}$ and 0.33 for $\mathrm{W}$ ), being almost constant in $f_{\text {cas }} \leqq 0.3$ (in reality 0.28 for $\mathrm{D}$ and 0.27 for $\mathrm{W}$ ) especially for $\mathrm{W}$ series. UFR for $\mathrm{D}$ series increases with an increase in $f_{\text {cas }}$ with sudden increase at $f_{\text {cas }} \geqq 0.3$. Such tendency was not observed for $\mathrm{W}$ series. $\sigma_{\mathrm{b}}$ is on the whole larger for $\mathrm{W}$ series than D series, both giving maximum at $f_{\text {cas }}=0.1$ (in reality 0.099 for $\mathrm{D}$ and 0.097 for W). Considerable increase in $\sigma_{\mathrm{b}}$ realizes at $f_{\text {cas }}=0.1$ for $\mathrm{W}$ series with keeping tensile elongation $\varepsilon_{\mathrm{b}}$ almost constant, compared with that for pure cellulose membrane. $\varepsilon_{\mathrm{b}}$ abruptly decreases when $f_{\text {cas }}$ goes up from 0.3 to 0.4 , suggesting that molecular chain entanglements between cellulose and casein becomes ineffective and macroscopic phase separation occurs in the above $f_{\text {cas }}$ region. The $f_{\text {cas }}$ range well corresponds to the $f_{\text {cas }}$ values reported previously. ${ }^{6}$ Swelling anisotropy parameter $L_{\mathrm{t}}$ is also depressed for the membranes with $f_{\text {cas }}=0.4$ but the swelling to width direction seems to decrease with an increase in $f_{\text {cas }}$. This means that the formation of sheet-like structure (or inter-planner hydrogen bond) characteristic to the regenerated cellulose during aq coagulation system ${ }^{11}$ is hindered by the existence of casein, which contains $43 \%$ hydrophobic and $57 \%$ hydrophilic amino acid residues, ${ }^{6}$ in the system with $f_{\text {cas }}$ range of $0.3-0.4$. All these parameters are plotted against $f_{\text {cas }}$ in Figure 1.

Figures $2 \mathrm{~A}$ and $\mathrm{B}$ show the SEM micrographs of the membranes (A: D series; B: W series. a, surface; b, cross section). Here, the surface mean the surface contacting coagulant. Obviously, the morphological distribution along thickness direction for all membranes is not so large on the whole, as was reported as a characteristic feature for the regenerated cellulose membranes obtained by aq sodium hydroxide coagulant from cellulose/cuprammoniun hydroxide system. ${ }^{11,12}$ Some voids are seen especially for $D$ series membranes. In any cases, the surface of $D$ series membranes except for $\mathrm{DCe}_{9} \mathrm{Ca}_{1}$ have far smaller pore than those for $\mathrm{W}$ series. The net work structure in which polymer particles are mutually connected to form pores are obvious especially for the surface of $\mathrm{W}$ series membranes.

Figure 3 shows CD spectra of cellulose/cuprammonium hydroxide and casein/cuprammonium hydroxide solutions (polymer concentration is $8 \mathrm{wt} \%$ and $20 \mathrm{wt} \%$, respectively). CD spectra reveal that cellulose exhibits a negative and positive $\mathrm{CD}$ peaks at wavelength $\lambda=c a$. $320 \mathrm{~nm}$ (charge transfer CT excitation) and $580 \mathrm{~nm}(\mathrm{~d}-\mathrm{d}$ excitation) with shoulders at longer $\lambda$ side (ca. 620 and $790 \mathrm{~nm}$ ), respectively and casein gives comparatively low intensity negative peaks at $c a .360$ and $520 \mathrm{~nm}$. This means that casein also has some molecular chain site to form some complex with cuprammonium hydroxide giving optical anisotropy. In this connect, casein is composed of at least 18 kinds of amino acids, of which glutamic acid content is largest $(22.7 \mathrm{wt} \%)$, as reported previously. ${ }^{6}$

Figures $4 \mathrm{~A}$ and $\mathrm{B}$ shows the $\mathrm{CD}$ spectra and the magnified UV spectra for $\mathrm{d}-\mathrm{d}$ excitation region of the mixed solutions. As $f_{\text {cas }}$ increases the CD intensity for CT excitation decreases keeping the peak position almost constant with an exception of the mixed solution with $f_{\text {cas }}=0.3$, which exhibits a shorter $\lambda$ shift and its intensity locates between those for $f_{\text {cas }}=0.1$ and 0.2 . Since the particular phenomenological event at $f_{\text {cas }}=0.3$ could not be considered the above reason is not clear at present. In the longer $\lambda$ region, a clear negative CD peak appeared at $c a .490-500 \mathrm{~nm}$ for the mixed solutions with $f_{\text {cas }} \geqq 0.3$ and the maximum peak for a positive broad envelope shifts to longer $\lambda$ side with an increase in $f_{\text {cas }}$ and the steep shift is observed $f_{\text {cas }} \geqq 0.3$. The appearance of negative CD peak at $c a .490-500 \mathrm{~nm}$ and the relatively steep longer wavelength shift for $\mathrm{d}-\mathrm{d}$ excitation might relate to the existence of the casein/cuprammonium hydroxide complex in the system, hence leading to an prediction that the mixed solutions with $f_{\text {cas }} \geqq 0.3$ is in the phase-separated state in an optical anisotropic sense. The UV spectra reveal that the maximum peak shifts towards shorter $\lambda$ side with an increase in $f_{\text {cas }}$ approaching the value for pure casein solution, and the absorbance once decreases by initial charge of casein to the system, then increasing with $f_{\text {cas }}$. These results imply that the

Table I. Mechanical properties of regenerated cellulose and blend membranes

\begin{tabular}{|c|c|c|c|c|c|c|c|c|}
\hline \multirow{2}{*}{ Sample No. } & \multirow{2}{*}{$\begin{array}{c}R e_{\text {cas }} \\
\%\end{array}$} & \multirow{2}{*}{$\begin{array}{c}P r_{\mathrm{a}} \\
\%\end{array}$} & \multirow{2}{*}{$\frac{\mathrm{UFR}}{\mathrm{mlh}^{-1} \mathrm{~m}^{-2} \mathrm{mmHg}^{-1}}$} & \multirow{2}{*}{$\frac{\sigma_{\mathrm{b}}}{\mathrm{kg} \mathrm{cm}^{-2}}$} & \multirow{2}{*}{$\begin{array}{l}\varepsilon_{\mathrm{b}} \\
\%\end{array}$} & \multicolumn{3}{|c|}{ Swelling parameters } \\
\hline & & & & & & $L_{\mathrm{t}}$ & $L_{1}$ & $V_{\mathrm{s}}$ \\
\hline $\mathrm{DCe}_{10} \mathrm{Ca}_{0}$ & - & 18.3 & 3.82 & 1224.4 & 8.3 & 1.62 & 1.16 & 2.18 \\
\hline $\mathrm{DCe}_{9} \mathrm{Ca}_{1}$ & 99 & 14.2 & 12.27 & 1360.9 & 13.1 & 1.83 & 1.13 & 2.34 \\
\hline $\mathrm{DCe}_{8} \mathrm{Ca}_{2}$ & 95 & 23.0 & 19.62 & 1219.9 & 8.4 & 1.89 & 1.08 & 2.20 \\
\hline $\mathrm{DCe}_{7} \mathrm{Ca}_{3}$ & 93 & 21.1 & 103.92 & 857.9 & 2.9 & 1.80 & 1.10 & 2.18 \\
\hline $\mathrm{DCe}_{6} \mathrm{Ca}_{4}$ & 93 & 50.6 & 132.34 & 437.5 & 1.0 & 1.46 & 1.09 & 1.73 \\
\hline $\mathrm{WCe}_{10} \mathrm{Ca}_{0}$ & - & 9.1 & 13.37 & 1288.1 & 11.3 & 1.84 & 1.14 & 2.39 \\
\hline $\mathrm{WCe}_{9} \mathrm{Ca}_{1}$ & 97 & 10.6 & 17.98 & 1738.6 & 11.4 & 1.79 & 1.13 & 2.29 \\
\hline $\mathrm{WCe}_{8} \mathrm{Ca}_{2}$ & 93 & 9.6 & 18.27 & 1501.5 & 11.1 & 1.99 & 1.10 & 2.41 \\
\hline $\mathrm{WCe}_{7} \mathrm{Ca}_{3}$ & 90 & 11.2 & 9.30 & 1393.8 & 9.0 & 1.88 & 1.10 & 2.27 \\
\hline $\mathrm{WCe}_{6} \mathrm{Ca}_{4}$ & 82 & 28.5 & 15.68 & 1043.9 & 6.5 & 1.71 & 1.09 & 2.03 \\
\hline
\end{tabular}



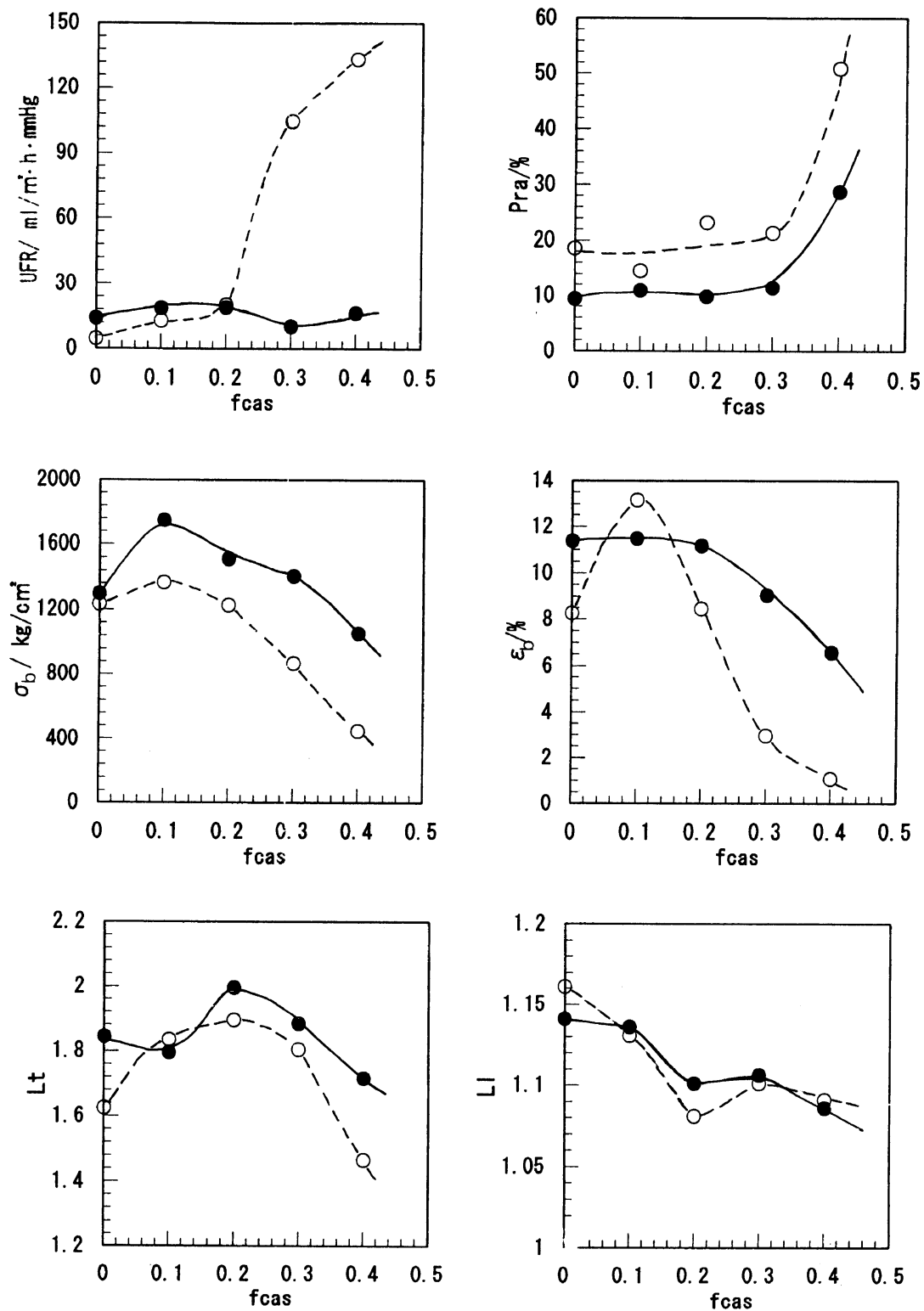

Figure 1. Structural parameters and properties as a function of $f_{\text {cas }} \bigcirc, \mathrm{D}$ series; $\bigcirc$, W series.

intermolecular interaction between functional groups (such as $\mathrm{COO}^{-}, \mathrm{NH}_{4}^{+}-\mathrm{NHCO}-$ ) of casein and $\mathrm{OH}^{-}$ group of cellulose and competitive formation of casein complex might lead to decrease in the amount of complex for cellulose/cuprammonium hydroxide in the mixed solutions.

Figures $5 \mathrm{~A}$ and $\mathrm{B}$ show the $\mathrm{CD}$ spectra for gel membranes of $\mathrm{D}$ and $\mathrm{W}$ series, respectively. A broad positive envelope (maximum peak position: 570 to $630 \mathrm{~nm}$ ) seen for the mixed solutions seems to separate into two peaks giving maximum peak around $690 \mathrm{~nm}$. A negative $C D$ peak attributable to casein/cuprammonium hydroxide becomes visible in the $f_{\text {cas }} \geqq 0.2$. All the results of CD measurements are summarized in Table II. Here, $\mathrm{CD}$ peak intensity for CT excitation region (below $\lambda=350 \mathrm{~nm}$ ) is not quantitative enough for discussion because the base lines are different from sample to sample and the different complex, if any, might give a different intensity of the CT excitation. The CD peak position for CT excitation for gel membranes with $f_{\text {cas }}=0.1$ is exceptionally longer with lowest intensity, abruptly shifting to shorter $\lambda$ when $f_{\text {cas }}$ goes from 0.1 to 0.2 for both $\mathrm{D}$ and $\mathrm{W}$ series. Similar inflection point $\left(f_{\text {cas }}=0.2\right)$ is also seen for the shorter wave number peak of $\mathrm{d}-\mathrm{d}$ excitation. If we compare the $\mathrm{CD}$ results for $\mathrm{W}$ and $\mathrm{D}$ series at $f_{\text {cas }}=0$ (that is, pure cellulose system), CT peak for $\mathrm{W}$ gel membrane is observed at far longer $\lambda$ by $c a .20 \mathrm{~nm}$ than that of $\mathrm{D}$ gel membrane, indicating that ammonia vaporization in advance leads to the gel complex different from so-called Norman compound of cellulose. Assuming that the retention of the Norman compound in cellulose parts of the gel membranes is a measure of a good molecular chain integration between cellulose and casein through the similar complex formation during alkaline coagulation so as to interfere with the independent phase-separation of casein, then such situation might be realized at $f_{\text {cas }} \leqq 0.1$ for $\mathrm{W}$ series and at $f_{\text {cas }}=c a$. 0.1 for $\mathrm{D}$ series judging from $\lambda$ values of CT excitation. This result might correlate with the largest $\sigma_{\mathrm{b}}$ values at $f_{\text {cas }}=0.1$. The abrupt shifting to shorter $\lambda$ when $f_{\text {cas }}$ goes from 0.1 to 0.2 for both $\mathrm{D}$ and $\mathrm{W}$ series may correspond to the clear appearance of the negative 
$\mathrm{DCe}_{10} \mathrm{Ca}_{0}$
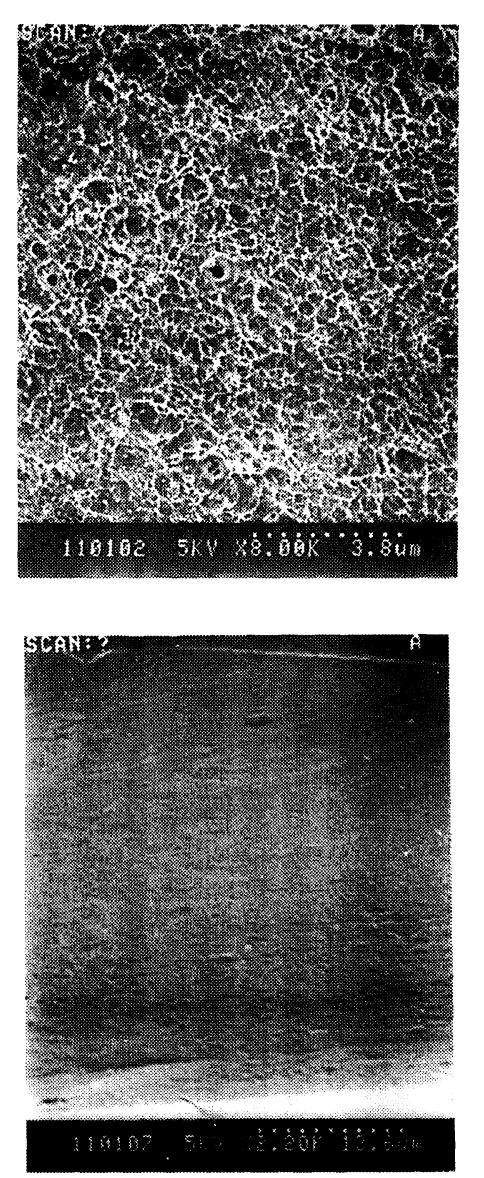

$\mathrm{DCe}_{9} \mathrm{Ca}_{1}$
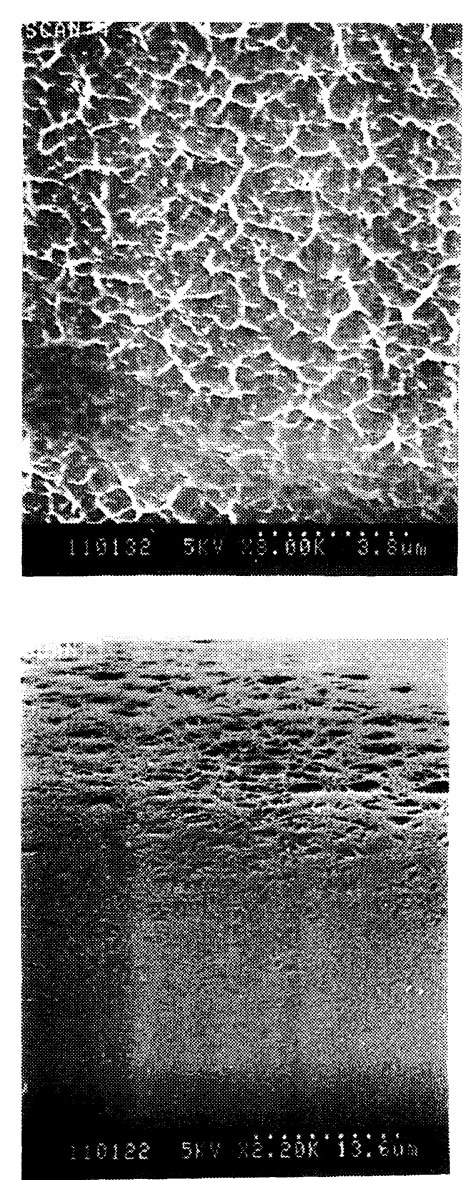

$\mathrm{DCe}_{8} \mathrm{Ca}_{2}$
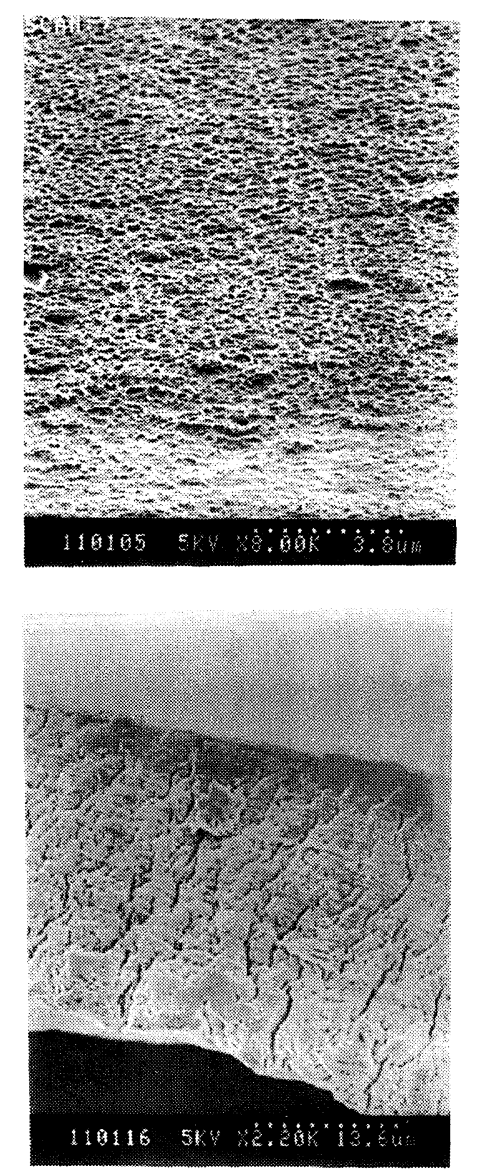

(A)
$\mathrm{DCe}_{7} \mathrm{Ca}_{3}$
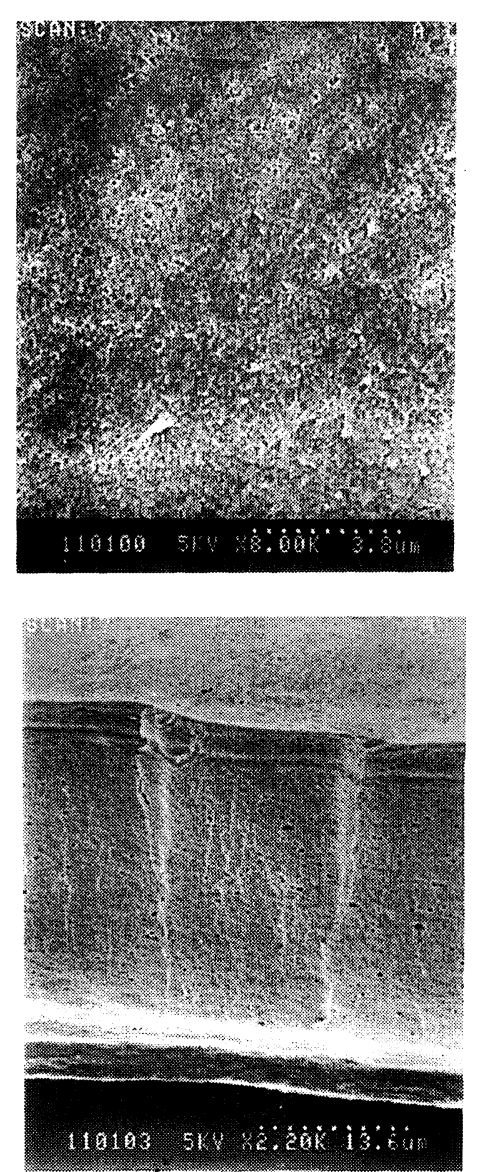

$\mathrm{DCe}_{6} \mathrm{Ca}_{4}$
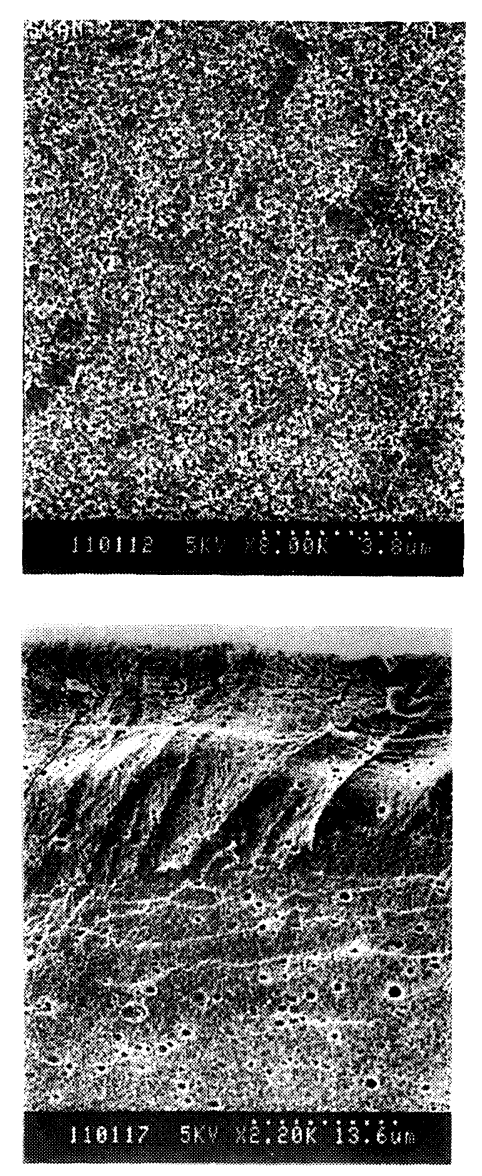

b) Cross

Figure 2 caption: see next page. 
$\mathrm{WCe}_{10} \mathrm{Ca}_{0}$
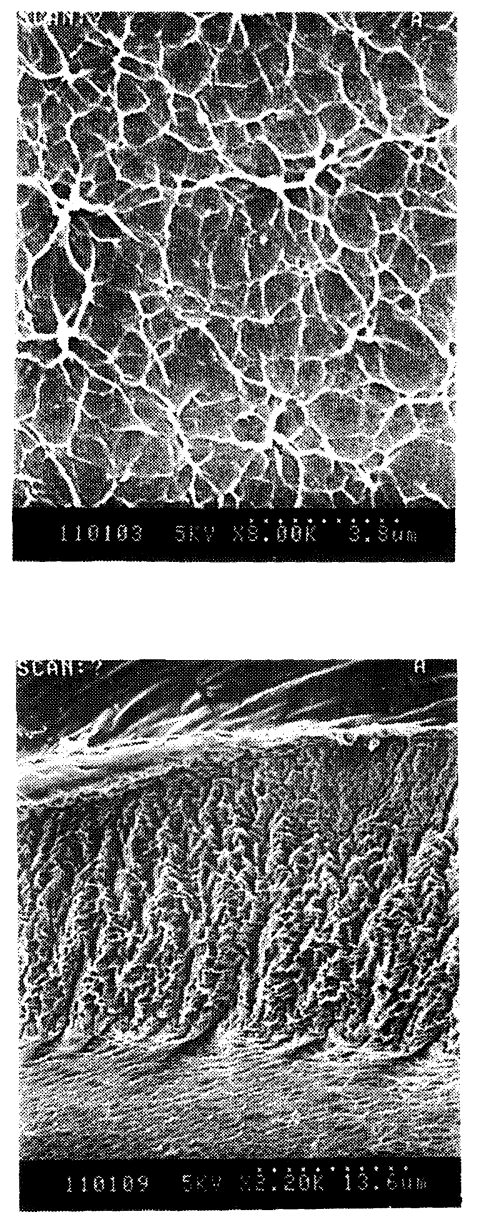

$\mathrm{WCe}_{9} \mathrm{Ca}_{1}$
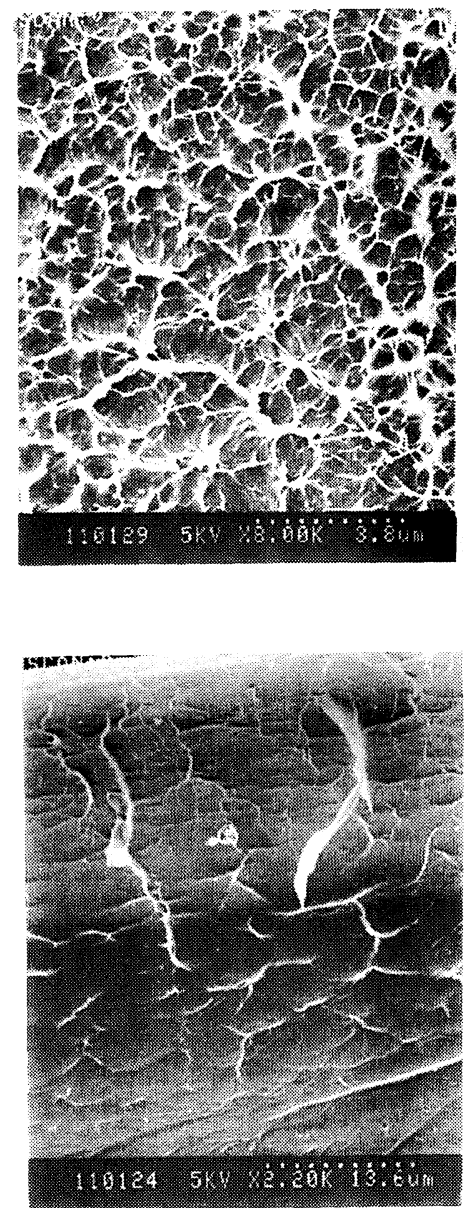

$\mathrm{WCe}_{8} \mathrm{Ca}_{2}$
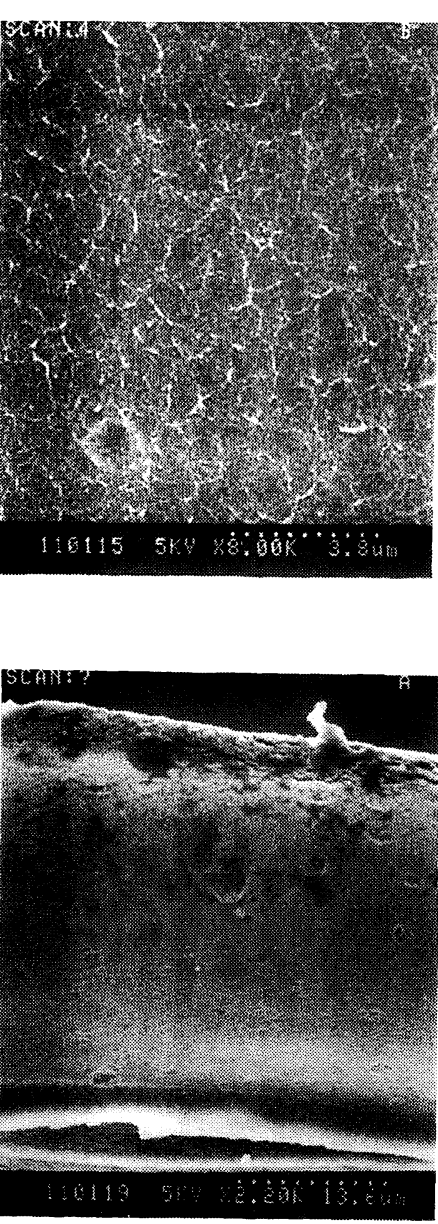

(B)
$\mathrm{WCe}_{7} \mathrm{Ca}_{3}$
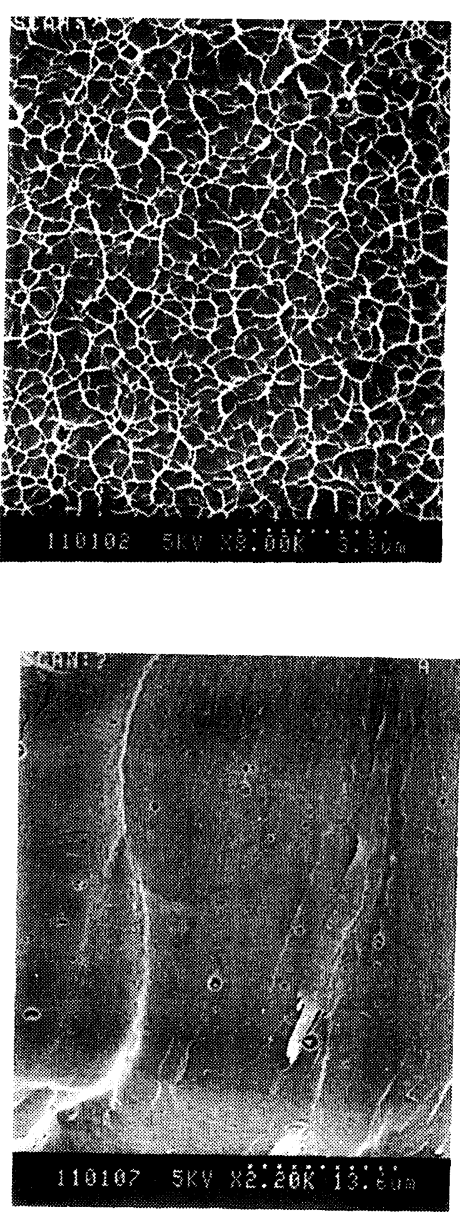

$\mathrm{WCe}_{6} \mathrm{Ca}_{4}$
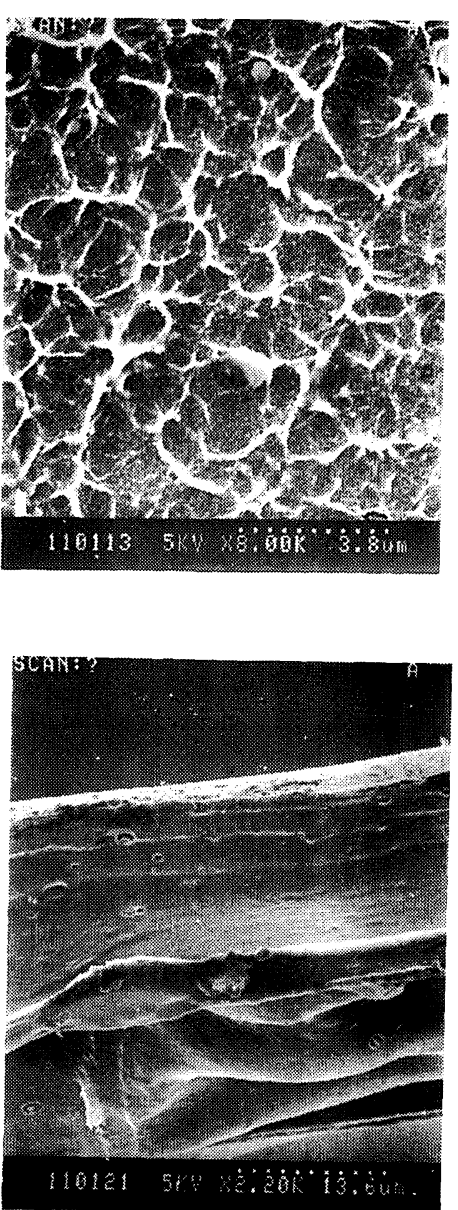

Figure 2. SEM of the membranes. (A), D series; (B), W series; a, surface; b, cross section. 


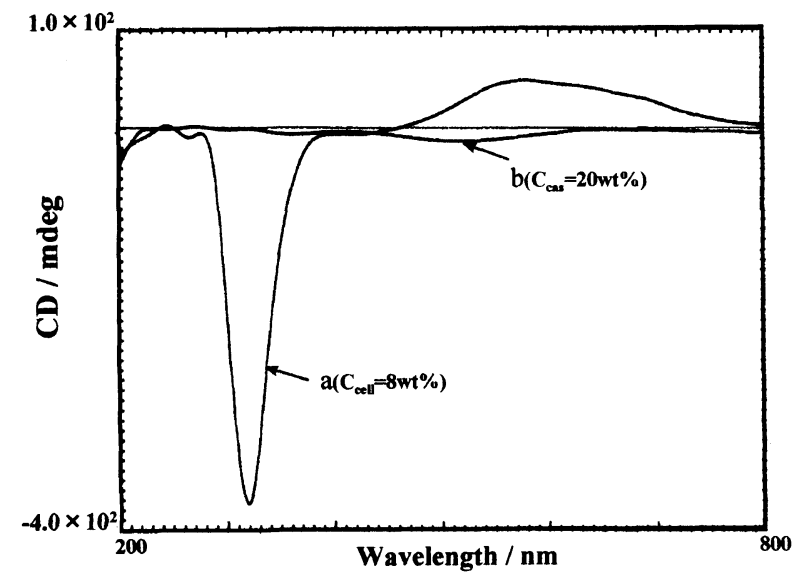

Figure 3. $\mathrm{CD}$ spectra of cellulose/cuprammonium hydroxide and casein/cuprammonium hydroxide. a) cellulose; b) casein.
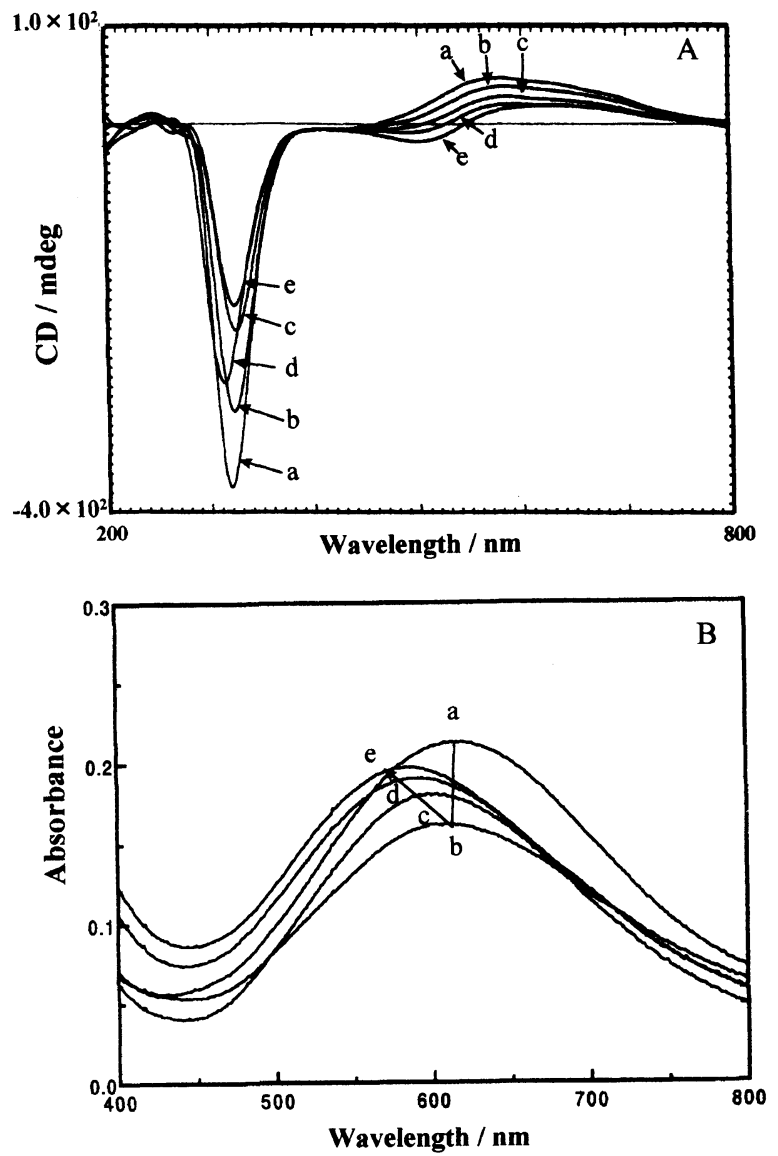

Figure 4. CD spectra (A) and the magnified UV spectra d-d excitation region (B) of the mixed solution. a) $f_{\text {cas }}=0$; b) $f_{\text {cas }}=0.1$; c) $f_{\text {cas }}=0.2$; d) $f_{\text {cas }}=0.3$; e) $f_{\text {cas }}=0.4$.

CD peak around $500 \mathrm{~nm}$ for casein/cuprammonium complex, suggesting the independent phase-separation of casein during coagulation. The $\lambda$ of $C D$ peaks for gel membranes with $f_{\text {cas }} \geqq 0.2$ is still longer than those for pure cellulose gel membranes.

Figures $6 \mathrm{~A}$ and $\mathrm{B}$ show X-ray diffraction patterns of the blend membranes (A, D series; B, W series) taken at different irradiation directions (a, perpendicular to membrane surface; $b$, parallel to membrane surface). For both series the patterns denature with an increase in $f_{\text {cas }}$. The diffraction peaks are seen at $2 \theta=7,12,19,22,28$, 34,36 , and $41^{\circ}$. The diffraction peak for (110) crystal
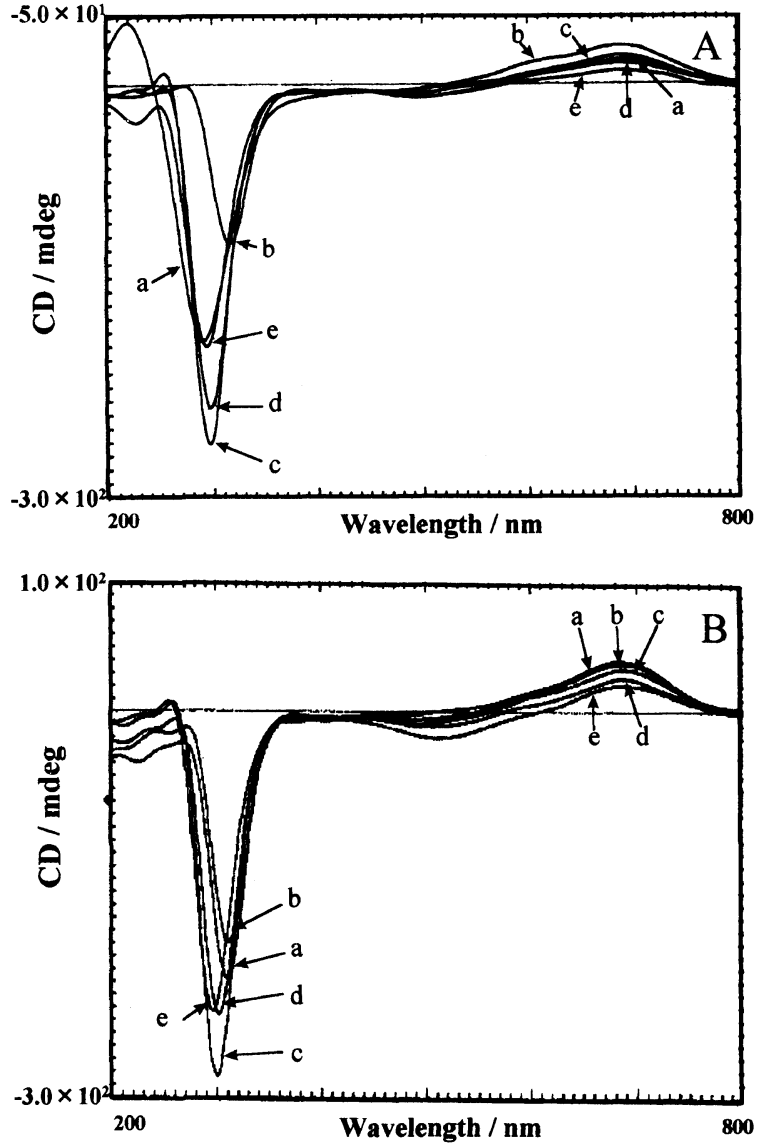

Figure 5. CD spectra for gel membranes of $\mathrm{D}$ series $(\mathrm{A})$ and $\mathrm{W}$ series (B). a) $f_{\text {cas }}=0$; b) $f_{\text {cas }}=0.1$; c) $f_{\text {cas }}=0.2$; d) $f_{\text {cas }}=0.3$; e) $f_{\text {cas }}=0.4$.

plane appeared at $2 \theta=12^{\circ}$ exhibits parallel orientation in general and the diffraction peak for the (200) crystal plane at $2 \theta=21^{\circ}$ is oriented to perpendicular direction. One more considerable perpendicular oriented peak is seen at $2 \theta=28^{\circ}$. The orientation factor of (110) plane to the parallel direction against membrane surface $f_{\|}(1 \overline{1} 0)$, crystal size estimated for (110) and (200) planes in both directions (parallel and perpendicular $\mathrm{d}$ to membrane surface) $\mathrm{ACS}_{\|}(110), \mathrm{ACS}_{\|}(200), \mathrm{ACS}_{\perp}(110)$, and $\mathrm{ACS}_{\perp}$ (200) as well as crystallinity $\chi_{\mathrm{c}}$ are plotted as a function of $f_{\text {cas }}$ in Figure 7. $\chi_{c}$, if compared between $\mathrm{D}$ and $\mathrm{W}$ series at same $f_{\text {cas }}$, is always higher for $\mathrm{W}$ series than $\mathrm{D}$ series and increases by the existence of casein though further charge of casein tends to lower $\chi_{\mathrm{c}}$ for D series. This means that ammonia contributes to some extent for crystallization of cellulose and casein facilitates crystallization of cellulose unless macroscopic structural fixation is not made before regeneration. $f_{\|}$(11) also tends to be larger for $\mathrm{W}$ series than $\mathrm{D}$ series and on the whole the existence of casein gives larger $f_{\|}(1 \overline{1} 0)$, being especially high for the blend membranes with $f_{\text {cas }}=0.1$, which corresponds well with the results for CD analysis on gel membranes. This indicates that proper amount of casein promotes the arrangement of hydrogen bonding of cellulose to membrane thickness direction. This in turn suggests that hydrogen bonding sites on casein also align to the membrane thickness direction by material transportation during coagulation process. $\mathrm{ACS}_{\perp}$ (110) and $\mathrm{ACS}_{\perp}$ (200) for $\mathrm{W}$ series membranes abruptly decreases with small charge of casein, then keeping 
Table II. The positions and intensities of $\mathrm{CD}$ peaks for the mixed solutions and gel membranes

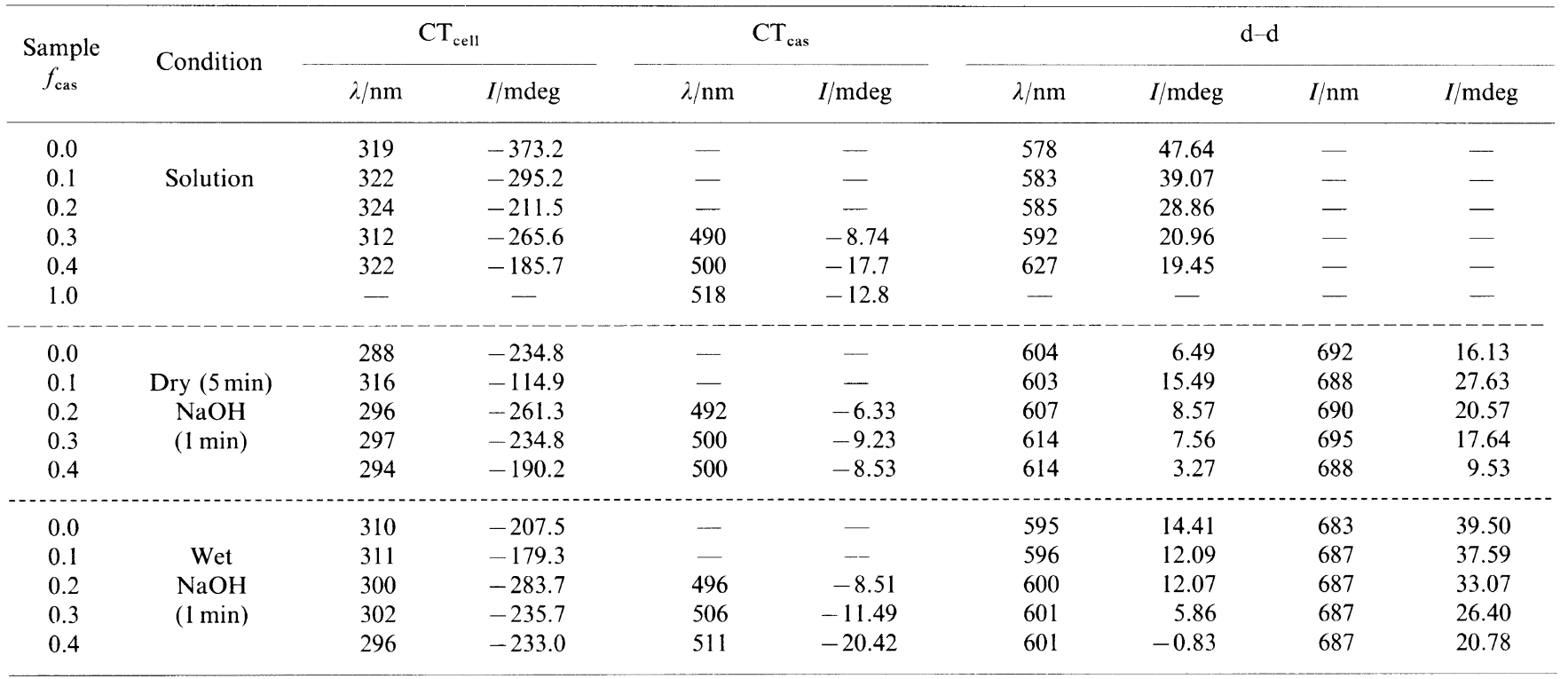

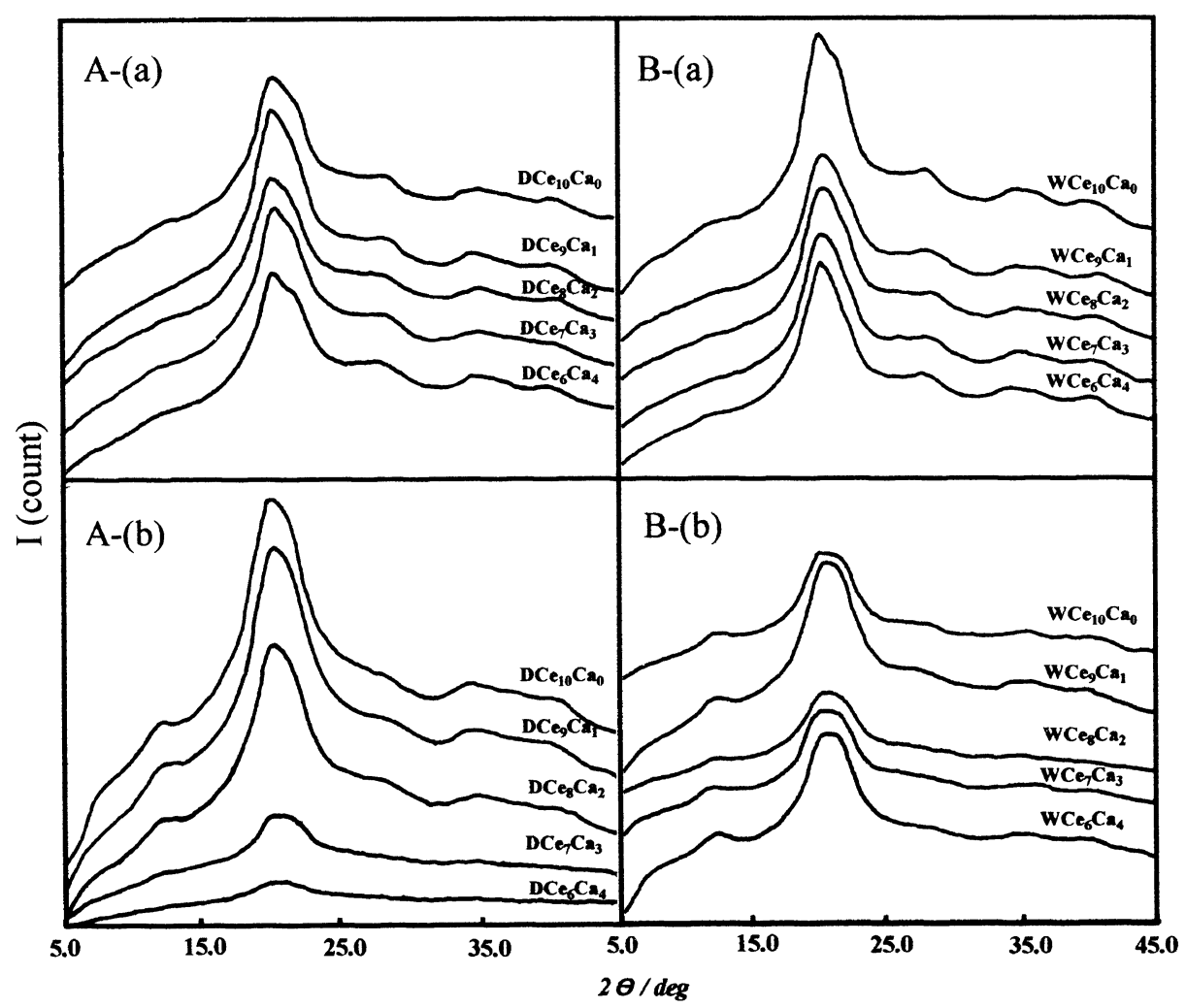

Figure 6. X-Ray diffraction patterns of the blend membranes. A, D series; B, W series; a, perpendicular to membrane surface $(\perp)$; b, parallel to membrane surface $(\|)$.

almost constant value. D series membranes exhibit a slight decrease in $\mathrm{ACS}_{\perp}$ (200) with almost constant $\mathrm{ACS}_{\perp}$ (110) as a function of $f_{\text {cas }} \cdot \mathrm{ACS}_{\perp}$ (200) for $\mathrm{D}$ series membranes is fairly larger than those for the blend membranes in $\mathrm{W}$ series, indicating that the advanced structural fixation interfere with the normal piling up of (200) plane, which is apt to orient parallel to membrane surface. $\mathrm{ACS}_{\|}$(110) for both W and D series tend to change similarly with $f_{\text {cas }}$, exhibiting a maximum at $f_{\text {cas }}=0.1$, followed by significant decrease in $f_{\text {cas }} \leqq 0.3$. Subsequent sudden increase in $\mathrm{ACS}_{\|}$(110) for W series

Polym. J., Vol. 29, No. 4, 1997 at $f_{\text {cas }}=0.4$ accompanies with a sudden decrease in $\mathrm{ACS}_{\|}$ (200). The facts that both $f_{\|}(1 \overline{10})$ and $\operatorname{ACS}_{\|}(110)$ give maximum at $f_{\text {cas }}=0.1$ suggest that appropriate amount of casein acts as also inner-planner bridge in (i 10$)$ planes as well as promoter of inter-planner hydrogen bonding

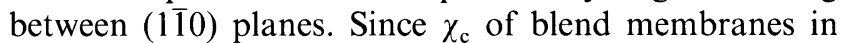
W series is slightly larger than that for pure cellulose membrane in W series, the decreasing of ACS means that number of crystalline nucleus increases by the addition of casein in the system. Abrupt increase in $\operatorname{Pr}_{\mathrm{a}}$ seen for the blend membrane with $f_{\text {cas }}=0.4$ accompanies the 

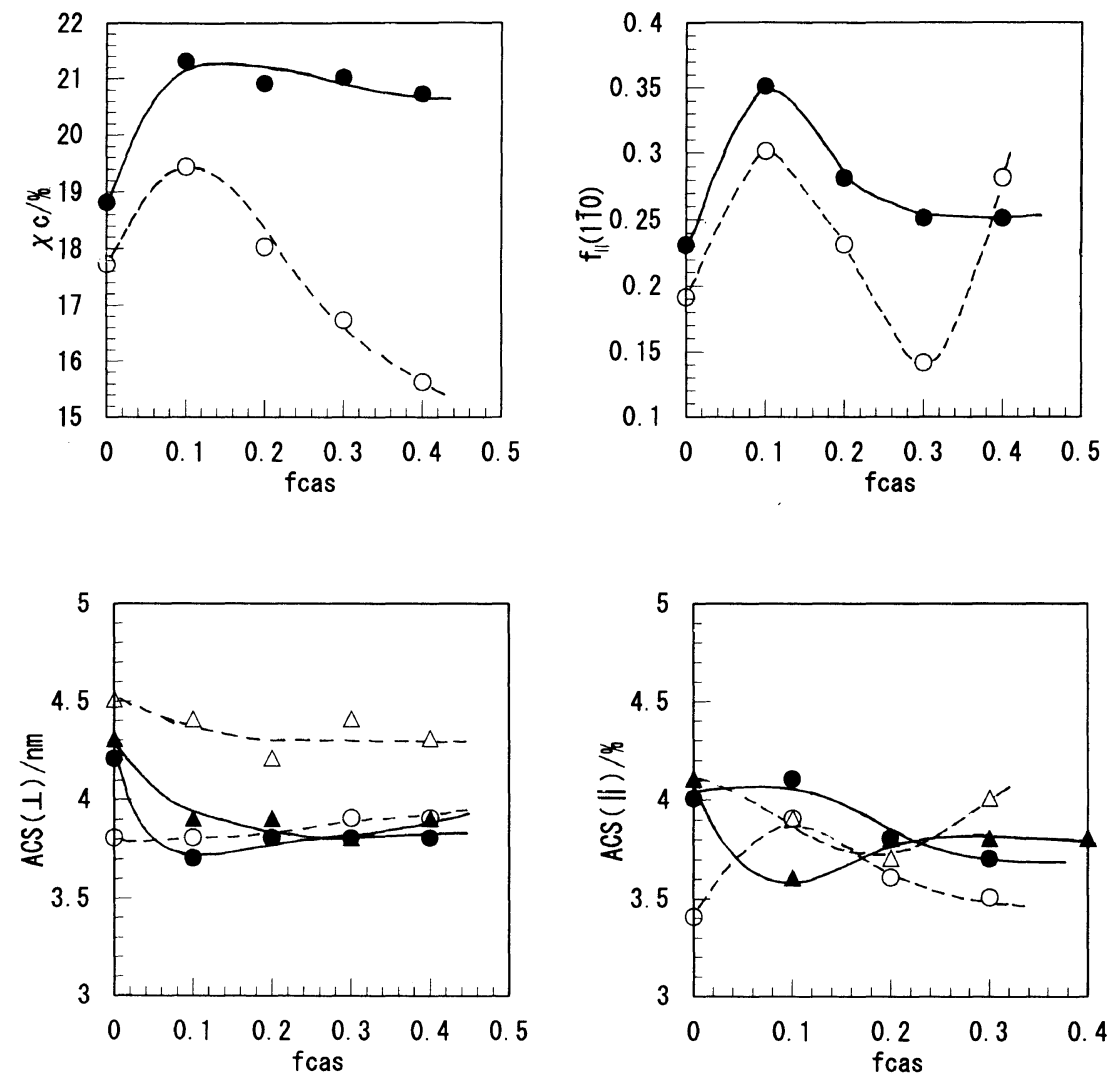

Figure 7. Crystallographic parameters as a function of $f_{\text {cas }}, O, \Delta$, D series; $\boldsymbol{\bullet}, \mathbf{\Delta}, \mathrm{W}$ series. In ACS figure: circular mark for 110 plane; triangle mark for 200 plane.

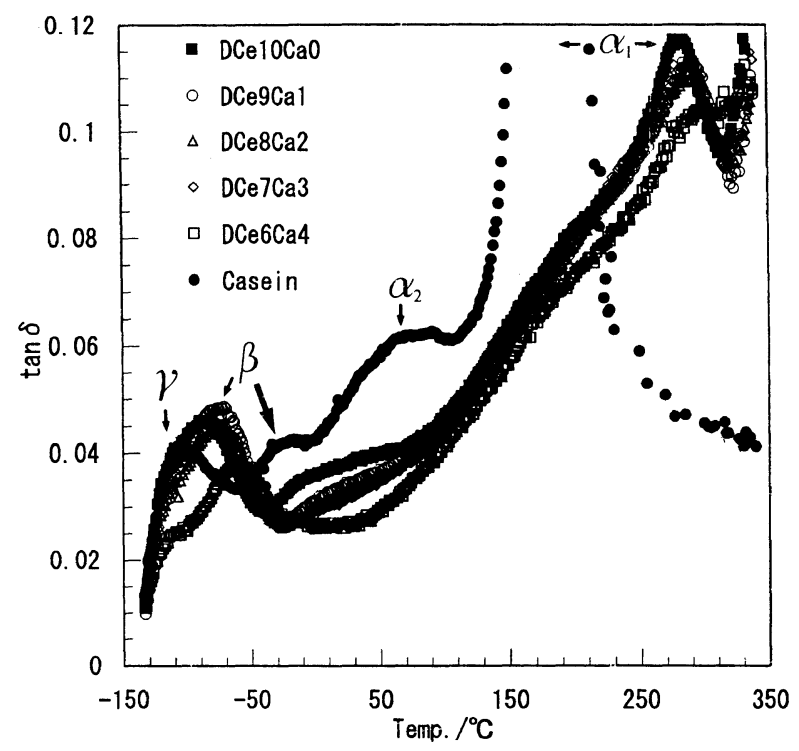

(A)

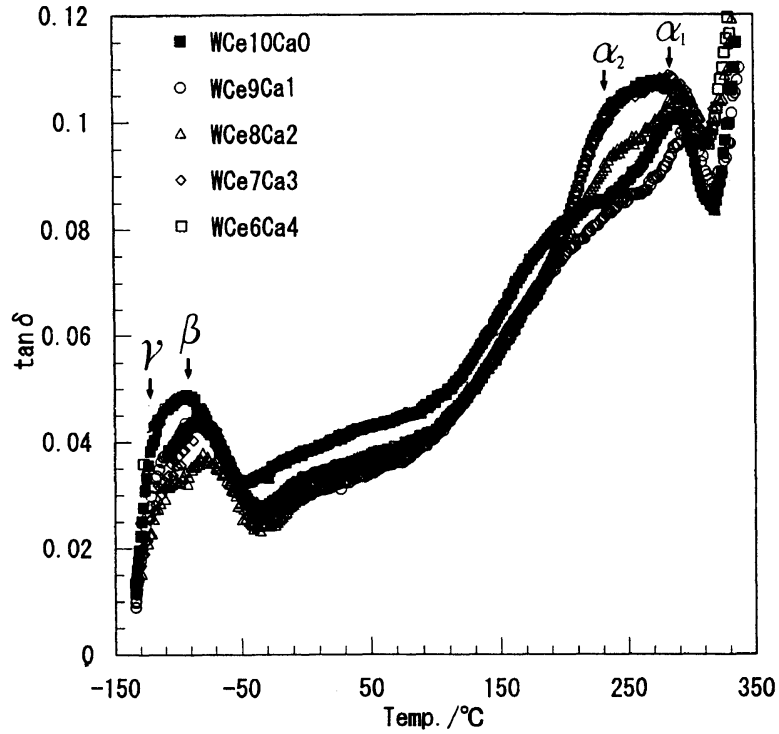

(B)

Figure 8. Loss tangent $\tan \delta$-temperature T curves for membranes. (A), D series; (B), W series.

increase of ACS of (110) plane and decreases of (200) plane.

Figures $8 \mathrm{~A}$ and $\mathrm{B}$ show the $\tan \delta-T$ curves for D and $\mathrm{W}$ series membranes, respectively and the former figure contains pure casein membrane. Casein gives relaxation peaks at $c a .180,83,-32$, and $-105^{\circ} \mathrm{C}$ and these are conveniently termed as $\alpha_{1}, \alpha_{2}, \beta$, and $\gamma$ from higher temperature side. Pure cellulose membrane in $\mathrm{W}$ series exhibits $\alpha_{1}, \alpha_{2}, \alpha_{\mathrm{sh}}, \alpha_{\mathrm{H}_{2} \mathrm{O}}, \beta_{1}, \beta_{2}$, and $\gamma$ from higher temperature side, as shown in the figure. The relaxation peaks are termed according to Manabe et al. ${ }^{17}$ For pure cellulose membrane in D series a sharp $\alpha_{1}$ is observed and $\alpha_{2}$ and $\alpha_{\mathrm{sh}}$ seem to merge as a broad shoulder for $\alpha_{1}$. For all blend membranes the peaks originated from casein seem not to be obvious due to the peak overlapping with those for cellulose. The $\beta$ relaxation for the blend membranes shifts to higher temperature side, rather showing that the main peak in $\beta$ relaxation region shifts from $\beta_{2}$ to $\beta_{1}$. The latter is associated with local segmental motion of in-phase hydrogen bond within a 
A
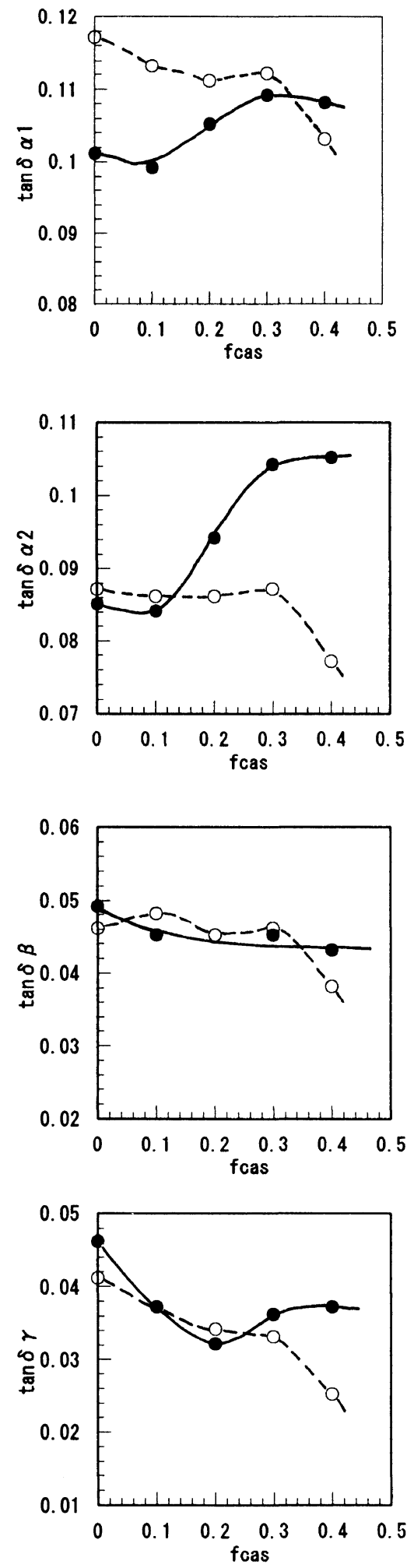

B
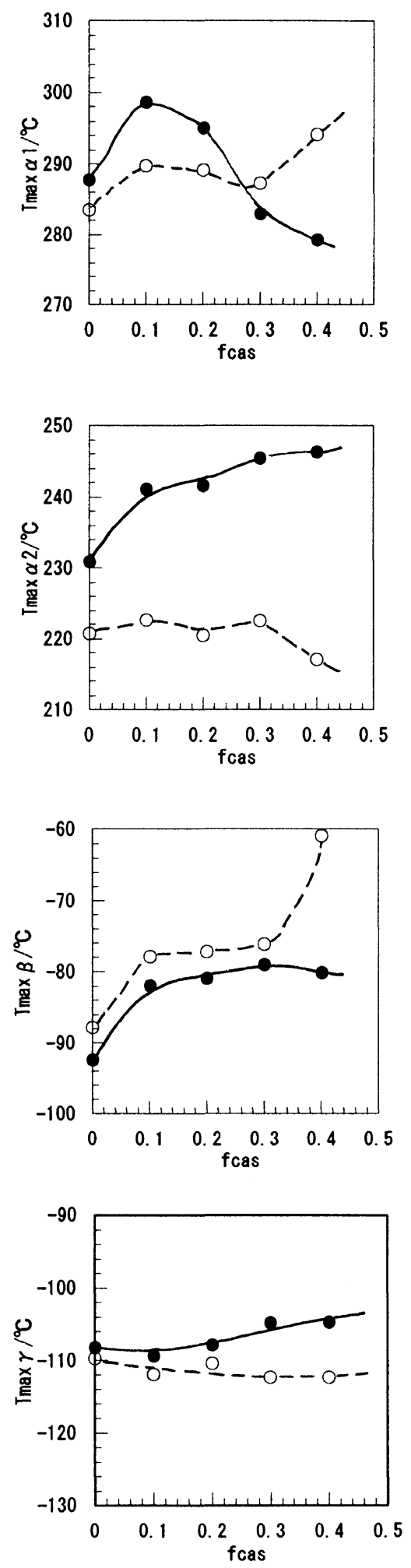

C
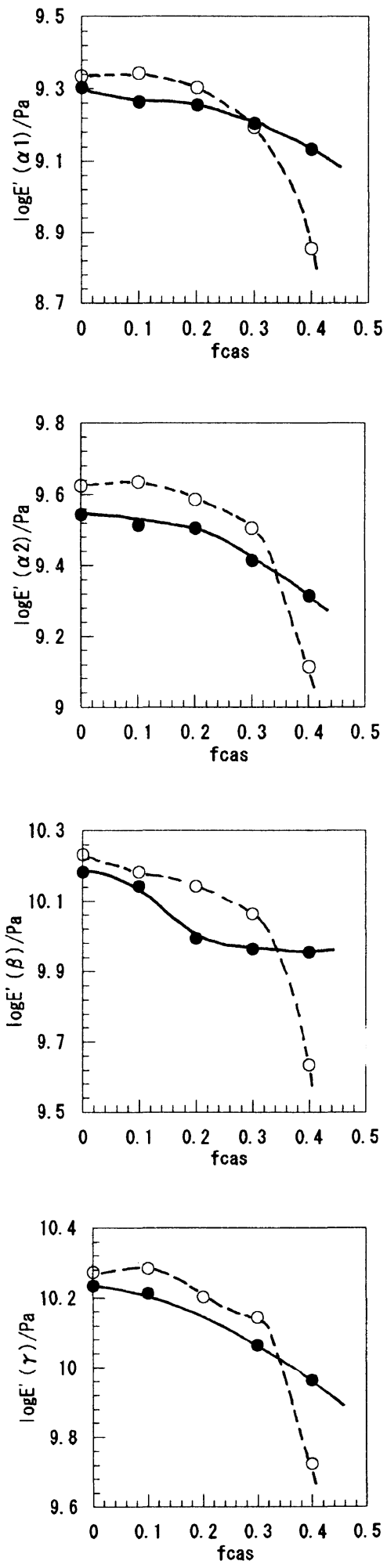

Figure 9. Dependence of amorphous parameters (A, tan $\delta_{\max } ; \mathrm{B}, T_{\max } ; \mathrm{C}, \operatorname{logarithmic}$ storage modules $\left.\log E^{\prime}\right)$ on $f_{\text {cas }} . \bigcirc, \mathrm{D}$ series;, $\mathrm{W}$ series.

plane-like structure in amorphous region, as was proposed previously. ${ }^{11}$ The $\alpha_{1}$ and $\alpha_{2}$ regions are broadened in $f_{\text {cas }} \geqq 0.3$ for $\mathrm{W}$ series membranes, compared with $\mathrm{D}$ series. The $E^{\prime}$ values are not normalized by polymer weight/unit area, only expressed in $\mathrm{Pacm}^{-2}$. All the amorphous parameters are plotted against casein fraction $f_{\text {cas }}$ in Figure 9. Quite contrast movements between $\mathrm{D}$ and $\mathrm{W}$ series are seen for $\tan \delta$ and $T_{\max }$ data.
For $\mathrm{D}$ series the critical changes are observed in $f_{\text {cas }} \geqq 0.3$ for almost all data including $E^{\prime}$ data, and the reverse critical changes are seen for $T_{\max \alpha 1}, T_{\max \alpha 2}, \tan \delta_{\max \alpha 1}$, and $\tan \delta_{\max \alpha 2}$ of $\mathrm{W}$ series in the $f_{\text {cas }}$ range of 0.1 to 0.3 . The former $f_{\text {cas }}$ range for $\mathrm{D}$ series corresponds to the $f_{\text {cas }}$ range where casein/cuprammonium hydroxide complex clearly appears in the mixed solution but not corresponds to the $f_{\text {cas }}$ range observed for the gel membranes in $\mathrm{D}$ 

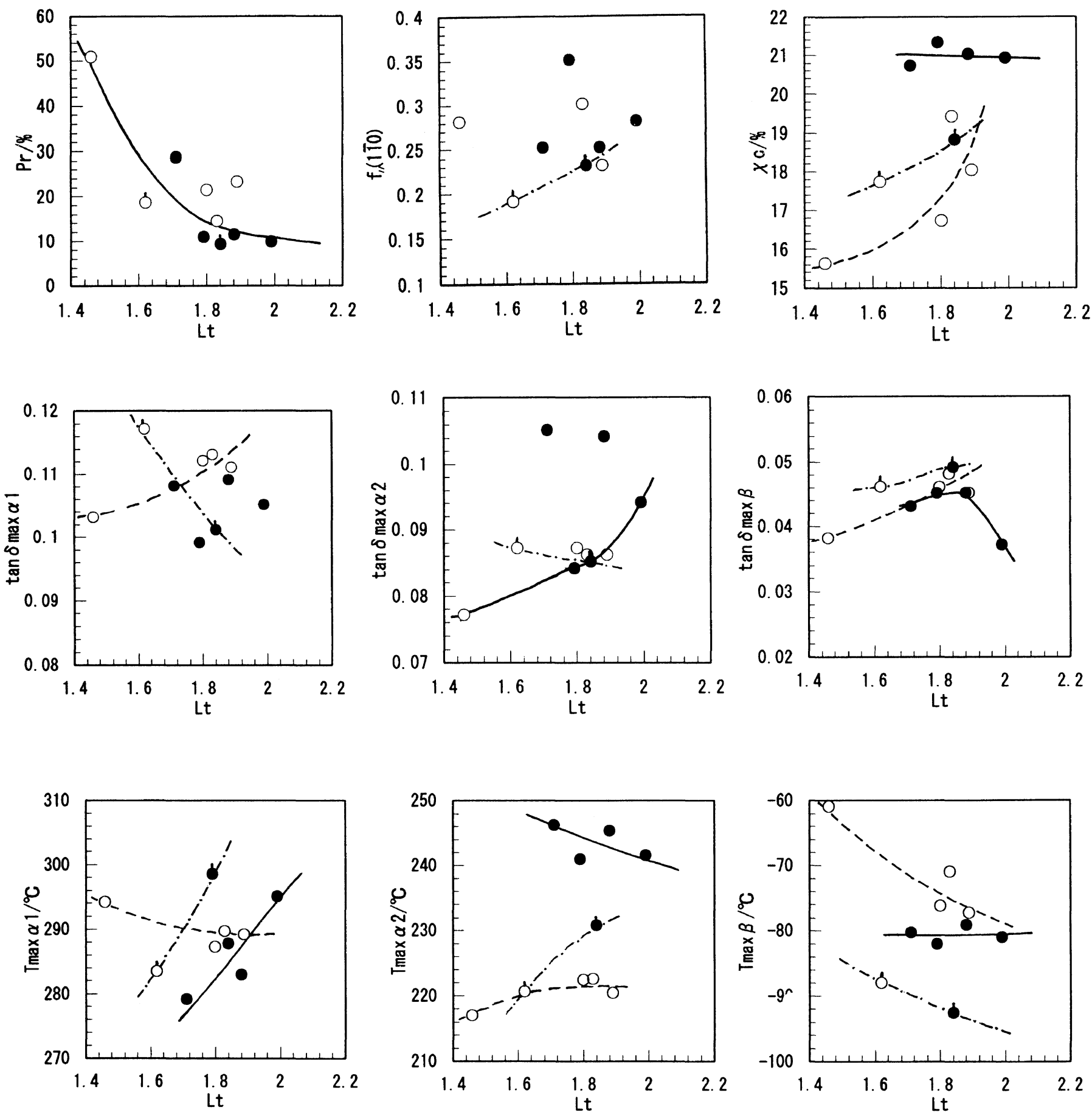

Figure 10. Dependence of structural and amorphous parameters on swelling anisotropy parameter $L_{1}, \mathrm{O}, \mathrm{D}$ series; $\boldsymbol{\bullet}, \mathrm{W}$ series.

series. This means that amorphous structure of the D series blend membranes is controlled by the structural fixation before regeneration process. The latter $f_{\text {cas }}$ range for $\mathrm{W}$ series includes the $f_{\text {cas }}$ range where gel membranes gives largest $\lambda$ for CT excitation and phase-separated state.

Structural parameters and properties are plotted in Figures $10-12$ in order to elucidate the factor controlling the properties. In addition crystal parameters are also plotted against amorphous parameters in Figures 13 and 14. In all the figures cellulose membranes in $\mathrm{D}$ and $\mathrm{W}$ series are symbolized as $\bigcirc$ and $\bigcirc$, respectively.

In our previous work, ${ }^{11}$ the swelling anisotropy parameter $L_{\mathrm{t}}$ for regenerated cellulose membranes has been found to well correlate with $P r_{\mathrm{a}}, f_{\|}(1 \overline{1} 0), \tan \delta$ and $T_{\max }$ for $\alpha_{2}$ and $\beta$ absorption. Then, this aspect was examined and is shown in Figure 10. For all plots the parameters for pure cellulose membranes (symbolized as $\delta$, seem to be outside the relation and will be neglected from the following analysis in general. This means that the swelling anisotropy of the blend membranes is controlled by another principle different from that for pure cellulose. However for both blend membranes (except for pure cellulose membranes), only $\operatorname{Pr}_{\mathrm{a}}$ was reconfirmed to correlate with $L_{\mathrm{t}}$ on the whole, being lower and larger for larger $L_{t}$, respectively. But other parameters deducted for regenerated cellulose membrane did not show any significant correlation. As 

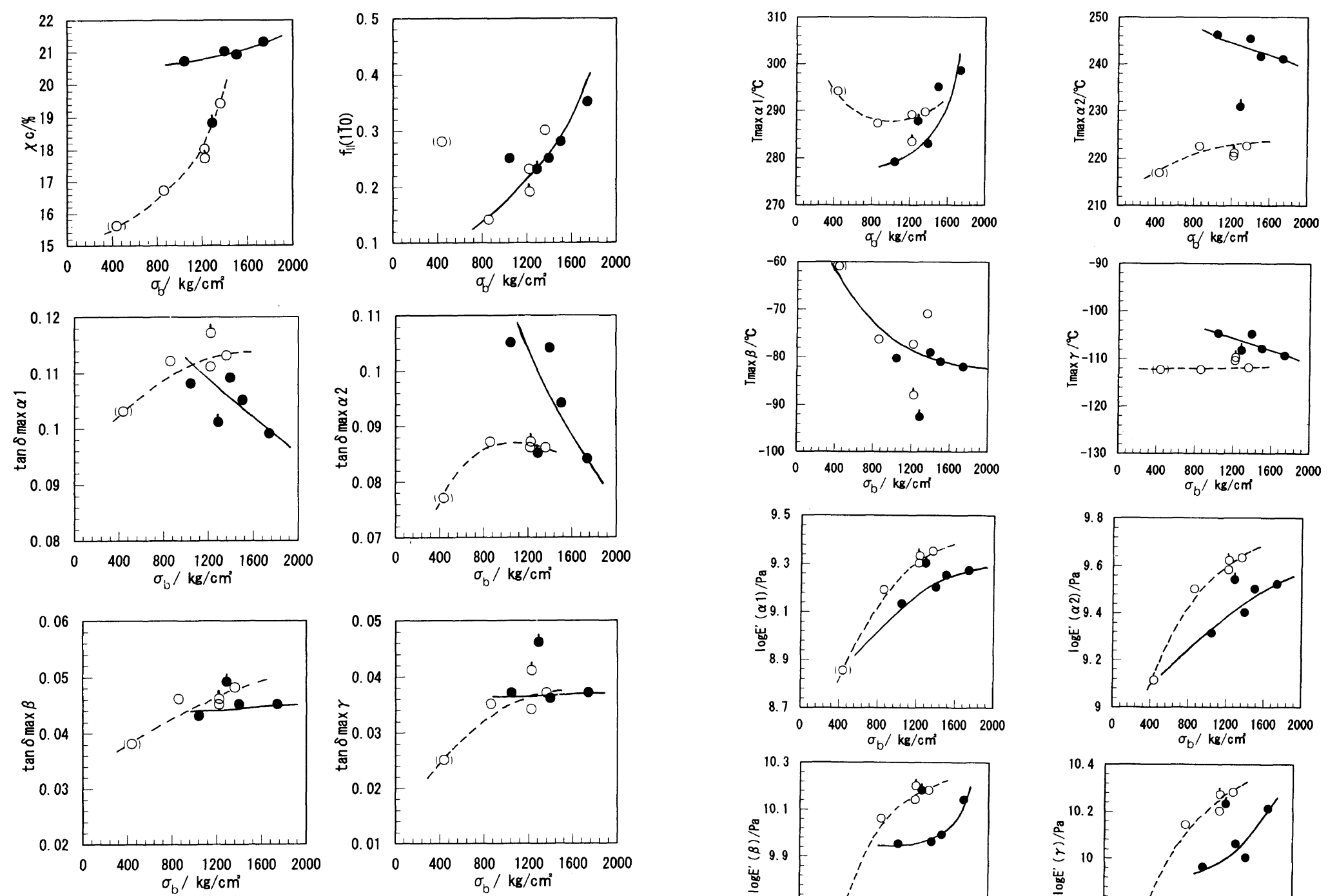

Fig. 11(1).
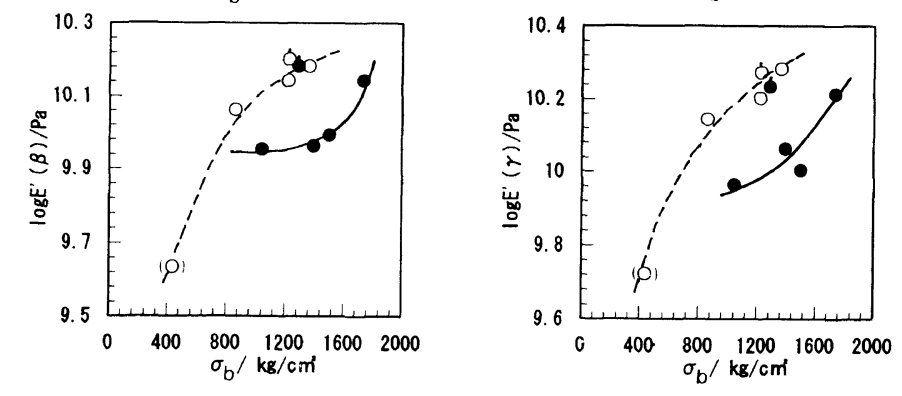

Fig. 11(2).

Figure 11. Dependence of structural and amorphous parameters on tensile strength $\sigma_{\mathrm{b}}, \mathrm{O}$, D series

W series. 

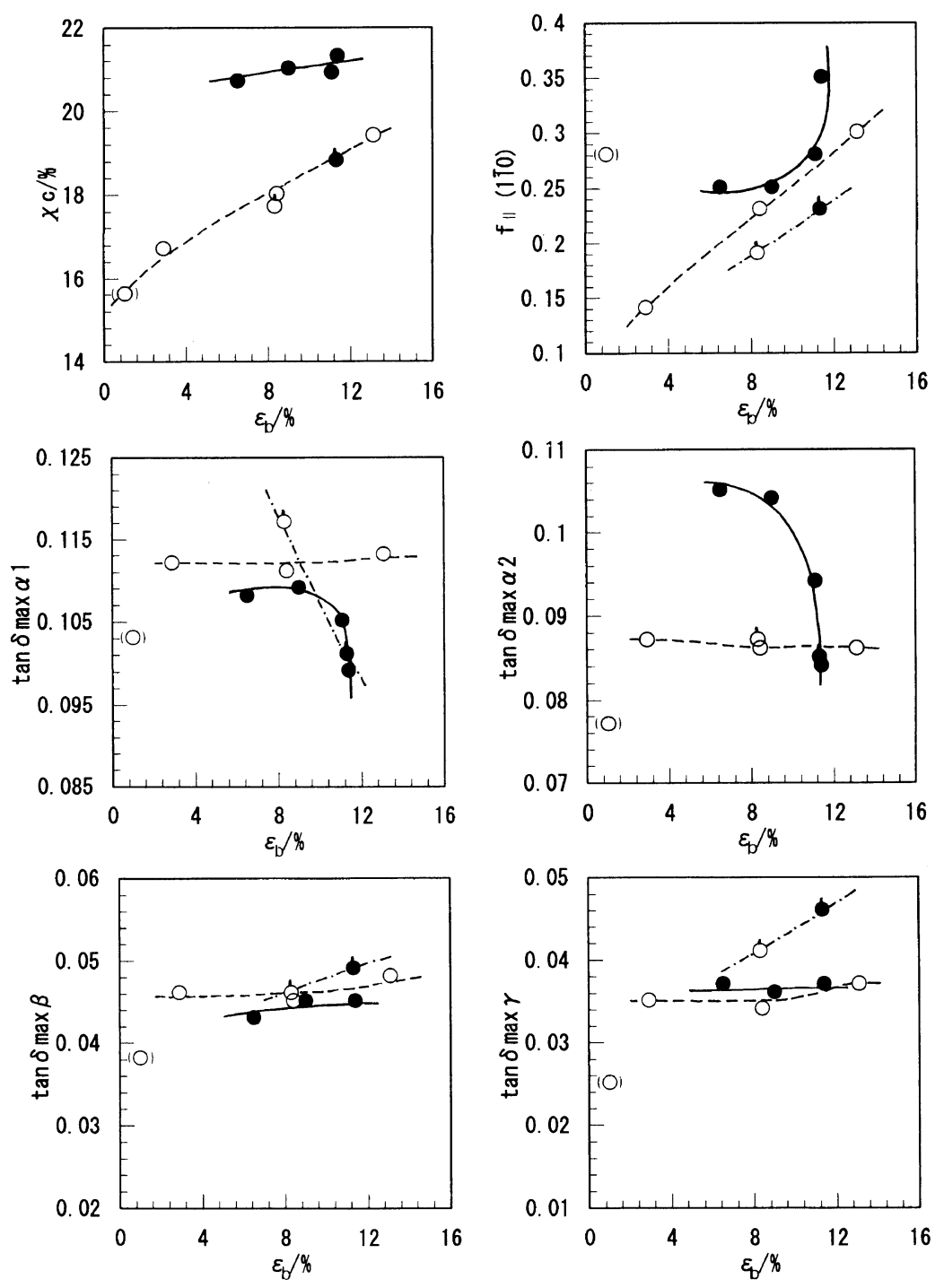

Fig. 12(1).

for the other parameters, $L_{\mathrm{t}}$ relations are quite different depending on $\mathrm{W}$ or $\mathrm{D}$ series. $L_{\mathrm{t}}$ of $\mathrm{W}$ series blend membranes is independent of $\chi_{\mathrm{c}}$ but that of $\mathrm{D}$ series blend membranes tends to increase with an increase in $\chi_{\mathrm{c}} . L_{\mathrm{t}}$ for $\mathrm{W}$ series blend membranes is an increasing function of $T_{\max \alpha 1}$ and a decreasing function of $T_{\max \alpha 2}$ but almost independent on $T_{\max \beta}$. On the one hand, $L_{\mathrm{t}}$ for $\mathrm{D}$ series blend membranes is an slightly decreasing functions of $T_{\max \alpha 1}$ and $T_{\max \beta}$ but a slightly increasing function of $T_{\max \alpha 2}$. Quite contrast dependence of $L_{\mathrm{t}}$ on $\chi_{\mathrm{c}}, T_{\max \alpha 1}, T_{\max \beta}$, and $T_{\max \alpha 2}$ for $\mathrm{D}$ and $\mathrm{W}$ series means principally that inter-molecular hydrogen bond formation for each series of membranes is considerably different. It is interesting to note that the changes in $T_{\max \alpha 1}$ and $T_{\max \beta}$ as a function of $L_{\mathrm{t}}$ for D series blend membranes are similar to those for regenerated cellulose membranes reported previously. ${ }^{11}$

Figure 11 tells us that tensile strength $\sigma_{\mathrm{b}}$ is reasonably increasing functions of $\chi_{\mathrm{c}}, f_{\|}(1 \overline{1} 0), T_{\max \alpha 1}$, and $\log E^{\prime}$ for both $\mathrm{D}$ and $\mathrm{W}$ series although they show their own master curves. Interestingly, $E^{\prime}$ values are always higher for D series than those for $\mathrm{W}$ series at same $\sigma_{\mathrm{b}}$ level nevertheless the lower $\chi_{\mathrm{c}}$ and $T_{\max \alpha 2}$. This phenomenon could be understood by very sharp $\tan \delta-T$ curve in $\alpha$ relaxation region for D series (see Figure 8), indicating that molec- ular chain packing density is higher for $\mathrm{D}$ than $\mathrm{W}$ series. Contrast dependences of $\sigma_{\mathrm{b}}$ for $\mathrm{W}$ and $\mathrm{D}$ series blend membranes are seen for $T_{\max \alpha 1}$ and $T_{\max \alpha 2}$, both of which decrease with an increase in $\sigma_{\mathrm{b}}$ for $\mathrm{W}$ series and the reverse is true for $\mathrm{D}$ series.

Figure 12 reveals that tensile elongation $\varepsilon_{\mathrm{b}}$ unexpectedly increases with an increase in $\chi_{\mathrm{c}}, f_{\|}(1 \overline{1} 0)$ and $\log E^{\prime}$ for both membranes although giving their own master curves. The dependence of $\varepsilon_{\mathrm{b}}$ on $E^{\prime}$ for D series is relatively smaller that that of $\mathrm{W}$ series. Except for $\mathrm{DCe}_{6} \mathrm{Ca}_{4} \tan \delta_{\max }$ for all relaxation and $T_{\max }$ for $\alpha_{1}, \beta$, and $\gamma$ are almost independent on $\varepsilon_{\mathrm{b}}$ for $\mathrm{D}$ series, suggesting that the elongation property of $\mathrm{D}$ series is mainly determined by macroscopic structure or morphology brought about ammonia vaporization. In contrast, in the case of $\mathrm{W}$ series $T_{\max }$ for $\alpha_{1}, \alpha_{2}$, and $\gamma$, and $\tan \delta_{\max }$ for $\alpha_{1}$ and $\alpha_{2}$ decrease with an increase in $\varepsilon_{\mathrm{b}}$, the latter two steeply decreasing at $\varepsilon_{\mathrm{b}} \geqq 9$. $T_{\max \alpha 1}$ for $\mathrm{W}$ series increases strongly with an increase in $\varepsilon_{\mathrm{b}}$. These results seem to point out that physical properties for $\mathrm{W}$ series membranes are dependent on amorphous structure formed by integration of casein and cellulose molecules.

Although $\chi_{\mathrm{c}}$ for $\mathrm{W}$ series is hard to find some relation with amorphous parameters due to very narrow range of $\chi_{c}$, its decreasing tendency is observed for $\tan \delta_{\max \alpha 1}$, 

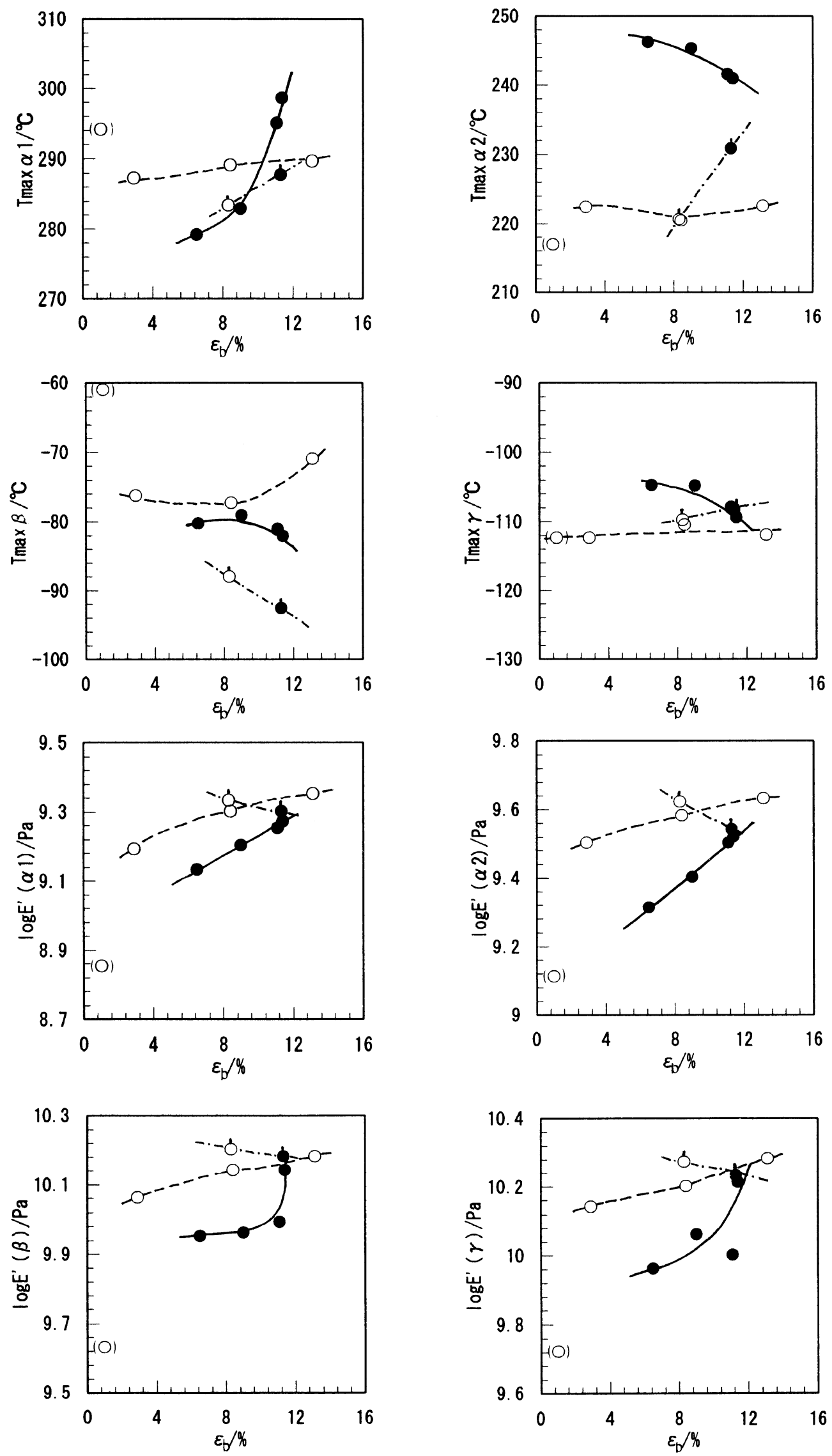

Fig. 12(2).

Figure 12. Dependence of structural and amorphous parameters on breaking elongation $\varepsilon_{\mathrm{b}} . \mathrm{O}, \mathrm{D}$ series; $\boldsymbol{\bullet}$, W series. 

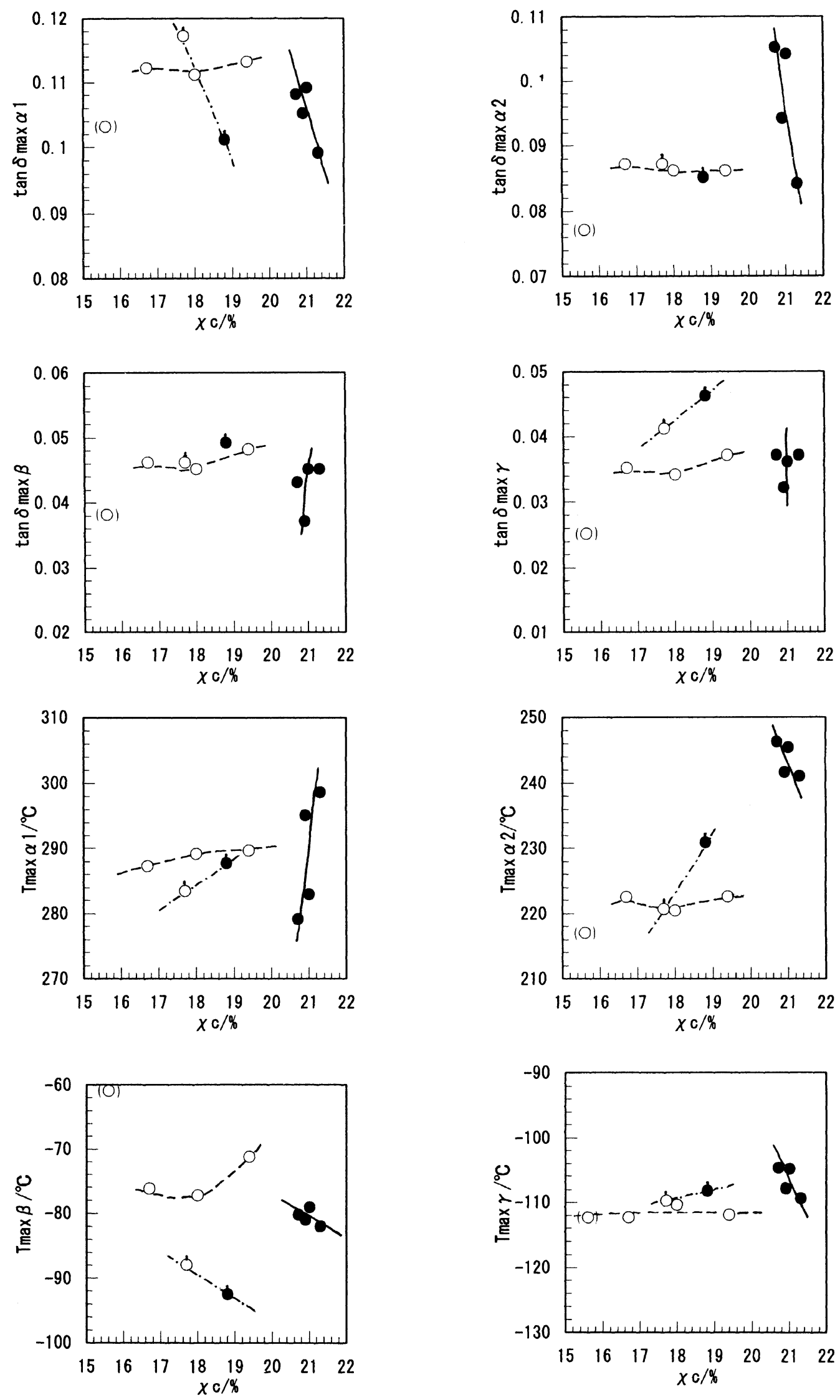

Figure 13. Dependence of amorphous parameters on crystallinity $\chi_{c} \cdot O, D$ series;,$w$ series.

$T_{\max }$ for $\alpha_{2}, \beta$, and $\gamma$, and $T_{\max \alpha 1}$ exhibits a steep increasing tendency, as shown in Figure 13. For D series blend membranes except for that with $f_{\text {cas }}=0.4$, of which $\sigma_{\mathrm{b}}$ and $\varepsilon_{\mathrm{b}}$ are exceptionally very low, $\chi_{\mathrm{c}}$ seems to give almost no dependence (or slight increasing dependence) on amorphous parameters, indicating again that amorphous structure of $\mathrm{D}$ series membranes are morphologydependent. 

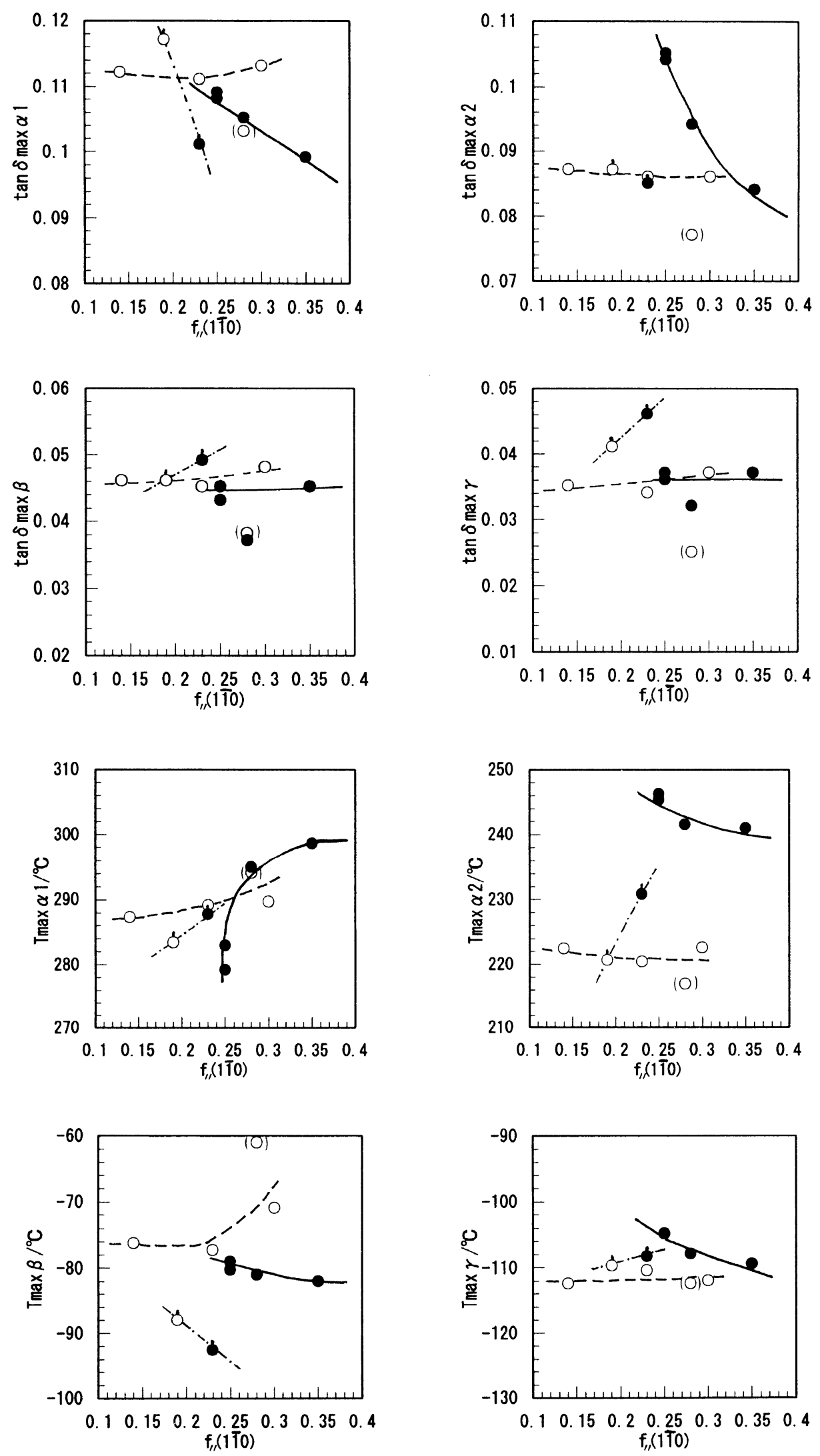

Figure 14. Dependence of structural and amorphous parameters on plane orientation parameter $f_{\|}(1 \overline{1} 0)$. $\bigcirc, \mathrm{D}$ series;, $\mathrm{W}$ series.

Almost similar influence on $f_{\|}(1 \overline{1} 0)$ of amorphous parameters is observed as shown in Figure 14. The abrupt decrease in $\tan \delta_{\max }$ for $\alpha_{1}$ and $\alpha_{2}$, a slight decrease in $T_{\max }$ for $\alpha_{2}, \beta$, and $\gamma$, an abrupt increase in $T_{\max \alpha 1}$ for $\mathrm{W}$ series are seen with an increase in $f_{\|}(1 \overline{1} 0) \cdot \tan \delta_{\max }$ for

Polym. J., Vol. 29, No. 4, 1997 $\beta$ and $\gamma$ for both series keep almost constant, and for D series $f_{\|}(1 \overline{1} 0)$ is also no dependence on amorphous parameters except for higher $T_{\max \alpha 1}$ and $T_{\max \beta}$ in larger $f_{\|}(1 \overline{1} 0)$, corresponding to tendency of $\chi_{\mathrm{c}}$. 


\section{CONCLUSION}

Circular dichroism (CD) measurements on the mixed solution of cellulose/casein in cuprammonium hydroxide solution and on their gel membranes by alkali coagulation directly or after vaporization of ammonia have been proved to be an effective tool for detecting the phase-separation in optical anisotropic sense. The results by $\mathrm{CD}$ measurements were successfully correlated with mechanical, crystallographic and visco-elastic properties of the blend membranes. The blend membranes with the weight fraction of casein $f_{\text {cas }}=0.1$ gave highest tensile strength and crystalline orientation and the corresponding gel membrane with $f_{\text {cas }}=0.1$ showed the longest wavelength $\mathrm{CD}$ peak for the charge transfer excitation of cellulose/cuprammonium complex. CD measurements on the mixed solution and gel membranes revealed that the mixed solution with the fraction of casein $f_{\text {cas }} \geqq 0.3$ forms the independent casein/cuprammonium hydroxide complex, hence giving phase-separated state in an optical anisotropic sense and this upper limit shifts towards lower $f_{\text {cas }}(=0.2)$ during coagulation. Mechanical relaxation analysis suggests that the amorphous structural formation for D and $\mathrm{W}$ series membranes are quite different and that for the former is on the whole determined by the morphological fixation brought about ammonia vaporization. Except for porosity $\operatorname{Pr}_{\mathrm{a}}$ the swelling anisotropy parameter $L_{\mathrm{t}}$ was not correlated with (110) plane orientation parameter and most amorphous parameters, which control $L_{\mathrm{t}}$ of the regenerated cellulose membranes.

\section{REFERENCES}

1. Y. Nishio, S. K. Roy, and R. S. J. Manley, Polymer, 28, 1385 (1987).

2. Y. Nishio and R. S. J. Manley, Macromolecules, 21, 1270 (1988).

3. Y. Nishio and R.S.J. Manley, Polym. Sci., 30, 71 (1990).

4. J. F. Masson and R.S.J. Manley, Macromolecules, 24, 5914 (1991).

5. E. Schweizer, J. Pract. Chem., 72, 109 (1857).

6. L. Zhang, G. Yang, and L. Xiao, J. Membrane Sci., 103, 65 (1995).

7. G. Yang and L. Zhang, Acta Polymerica Sinica, 2, 48 (1994).

8. G. Yang and L. Zhang, J. Membrane Sci., 114, 149 (1996).

9. I. Miyamoto, M. Inamoto, T. Matsui, M. Saito, and K. Okajima, Polym. J., 27, 1113 (1995).

10. M. Inamoto, I. Miyamoto, T. Hongo, M. Iwata, and K. Okajima, Polym. J., 28, 6, 507 (1996).

11. T. Hongo, C. Yamane, M. Saito, and K. Okajima, Polym. J., 28, 769 (1996).

12. T. Hongo, T. Koizumi, C. Yamane, and K. Okajima, Polym. J., 28, 1077 (1996).

13. M. Inamoto, T. Hongo, M. Iwata, T. Matsui, and K. Okajima, Submitted to J. Appl. Polym. Sci.

14. W. Brown and R. Wikstrom, Eur. Polym. J., 1, 1 (1965).

15. T. Takahashi, Sen-i Gakkaishi, 25, 80 (1969).

16. P. Scherrer, Gottinger Nachr., 2, 98 (1918).

17. S. Manabe, M. Iwata, and K. Kamide, Polym. J., 18, 1 (1986). 